\title{
Tuning the coordination environment in single-atom catalysts to achieve highly efficient oxygen reduction reactions
}

Jinqiang Zhang ${ }^{1, \dagger}$, Yufei Zhao ${ }^{1, \dagger}$, Chen Chen ${ }^{2, *}$, Yu-Cheng Huang ${ }^{3}$, Chung-Li Dong ${ }^{3}$, ChihJung Chen ${ }^{4}$, Ru-Shi Liu ${ }^{4,5,}$, Chengyin Wang ${ }^{6}$, Kang Yan ${ }^{1}$, Yadong Li ${ }^{2, *}$, Guoxiu Wang ${ }^{1, *}$

${ }^{1}$ Center for Clean Energy Technology, School of Mathematical and Physical Sciences, Faculty of Science, University of Technology Sydney, NSW 2007, Australia. Guoxiu.Wang@uts.edu.au

${ }^{2}$ Department of Chemistry and Collaborative Innovation Center for Nanomaterial Science and Engineering, Tsinghua University, Beijing 100084, China. cchen@mail.tsinghua.edu.cn, ydli@mail.tsinghua.edu.cn

${ }^{3}$ Department of Physics, Tamkang University, Tamsui 25137, Taiwan

${ }^{4}$ Department of Chemistry, National Taiwan University, Taipei 10617, Taiwan. rsliu@ntu.edu.tw

${ }^{5}$ Department of Mechanical Engineering and Graduate Institute of Manufacturing Technology, National Taipei University of Technology, Taipei 10608, Taiwan

${ }^{6}$ College of Chemistry and Chemical Engineering, Yangzhou University, Jiangsu, P. R. China $\uparrow$ These authors contributed equally to this work. 


\section{Experimental}

Synthesis of the silica sphere: the silica nanospheres were prepared by using the Stöber method. Typically, TEOS (tetraethyl orthosilicate, $6 \mathrm{ml})$ was added into ethanol $(210 \mathrm{ml})$ under stirring. Then ammonium hydroxide $(25 \mathrm{wt} \%, 7.2 \mathrm{ml})$ and water $(42 \mathrm{ml})$ were added to the above solution dropwise. The mixture was kept at room temperature for $24 \mathrm{~h}$ under stirring, forming the white suspension. The solid precipitate was subsequently separated by using the centrifuge at $8500 \mathrm{rpm}$ for $10 \mathrm{~min}$ and washed by water and ethanol for 3 times. Finally, the $\mathrm{SiO}_{2}$ nanospheres were obtained in the vacuum oven at $65^{\circ} \mathrm{C}$ for $12 \mathrm{~h}$.

Synthesis of the nitrogen and sulfur co-doped carbon (NSC): the doped carbon were fabricated by using the silica nanospheres as the template. Briefly, 1-allyl-2-thiourea (1.0 g) and silica nanospheres $(1.0 \mathrm{~g})$ were mixed in the deionized water $(5 \mathrm{ml})$ in a glass bottle at $80{ }^{\circ} \mathrm{C}$ for $2 \mathrm{~h}$. The 1-allyl-2-thiourea can dissolve quite well at $80{ }^{\circ} \mathrm{C}$ because the melting point of 1-allyl-2-thiourea is $70-72{ }^{\circ} \mathrm{C}$. The dissolved 1-allyl-2-thiourea can form a clear solution in the deionized water, facilitating its adsorption on the template (silica sphere) surface. The dried 1-allyl-2-thiourea coated silica nanospheres can be obtained by a slow evaporation process $\left(60{ }^{\circ} \mathrm{C}\right.$ in the oven). The achieved above samples were calcined at $900{ }^{\circ} \mathrm{C}$ for $3 \mathrm{~h}$ under an inert atmosphere. The ramp rate of the carbonization process is $5{ }^{\circ} \mathrm{C} \mathrm{min}^{-1}$. The final product, nitrogen, and sulfur co-doped carbon, was obtained by removing the silica nanospheres template by using $5 \mathrm{M} \mathrm{NaOH}$ hot solution.

Synthesis of the single metal atom/NSC (M-SAs/NSC, M=Fe, Co Ni) catalysts: the M$\mathrm{SAs} / \mathrm{NSC}$ (Fe, Co Ni-SAs/NSC) were also fabricated by using the silica nanospheres as the template. Typically, 1-allyl-2-thiourea $(1.0 \mathrm{~g})$ and silica nanospheres $(1.0 \mathrm{~g})$ were mixed in the deionized water $(5 \mathrm{ml})$ with $5 \mathrm{mg} \mathrm{Fe}\left(\mathrm{NO}_{3}\right)_{3}, \mathrm{Co}\left(\mathrm{NO}_{3}\right)_{2}, \mathrm{Ni}\left(\mathrm{NO}_{3}\right)_{2}$ in a glass bottle at $80{ }^{\circ} \mathrm{C}$ for $2 \mathrm{~h}$, respectively. The dissolved 1-allyl-2-thiourea and metal precursor can form a clear solution in the deionized water, facilitating its adsorption on the template (silica sphere) surface. The samples can be obtained by a slow evaporation process $\left(60^{\circ} \mathrm{C}\right.$ in the oven). The achieved above materials were then calcined at $900{ }^{\circ} \mathrm{C}$ for $3 \mathrm{~h}$ under an inert atmosphere. The ramp rate of the carbonization process is $5{ }^{\circ} \mathrm{C} \mathrm{min}^{-1}$. The final product, M-SAs/NSC (Fe-SAs/NSC, CoSAs/NSC, Ni-SAs/NSC), was obtained by removing the silica nanospheres template by using 
$5 \mathrm{M} \mathrm{NaOH}$ hot solution and then acid leaching.

\section{Characterization}

The morphology and chemical composition of the as-prepared samples were characterized by field emission scanning electron microscopy (FESEM, Zeiss Supra 55VP), electron energy dispersive spectroscopy (Zeiss Evo SEM), and transmission electron microscopy (TEM, Model JEM-2010, JEOL) and scanning transmission electron microscopy (STEM, JEOL JEMARM200F). X-ray diffraction (XRD) measurements were conducted by employing a scanning step of $0.04^{\circ}$ per second in the $2 \theta$ range from 3 to $80^{\circ}$ (Bruker D8 Discover XRD). X-ray photoelectron spectroscopy (XPS) measurement was performed on an ESCALAB250Xi (Thermo Scientific, UK) equipped with mono-chromatic Al K alpha (energy $1486.68 \mathrm{eV}$ ). Raman spectra were collected on an inVia Renishaw Raman spectrometer system (HR Micro Raman spectrometer, Horiba JOBIN YVON US/ HR800 UV) using a $632.8 \mathrm{~nm}$ wavelength laser. The content of the metal was measured on inductively coupled plasma-mass spectrometry (ICP-MS) on an Optima 7300 DV (Perkin-Elmer Corporation). The Brunauer-Emmett-Teller (BET) surface area of the obtained materials was measured by using experimental points at a relative pressure of $\mathrm{P} / \mathrm{P}_{0}=0.05-0.25$. The $\mathrm{X}$-ray absorption near-edge spectroscopy (XANES) and extended X-ray absorption fine structure (EXAFS) at Fe, Co and Ni $K$-edge were recorded in transition mode at beamline BL01C1 at the National Synchrotron Radiation Research Center (NSRRC), Taiwan. Fe foil, $\mathrm{Co}$ foil, $\mathrm{Ni}$ foil, $\mathrm{FeO}, \mathrm{Fe}_{2} \mathrm{O}_{3}$, iron phthalocyanine (FePc), $\mathrm{CoO}$, $\mathrm{Co}_{3} \mathrm{O}_{4}$, cobalt phthalocyanine $(\mathrm{CoPc}), \mathrm{NiO}$, and nickel phthalocyanine $(\mathrm{NiPc})$ were used as reference samples. Data analysis was carried out with Athena and Artemis included in the Demeter package. The quantitative curve-fittings were carried out in the $k^{3}$-weighted EXAFS oscillation in the range of 0-6 A using the module ARTEMIS of IFEFFIT.

\section{Electrochemical Measurements}

All the electrochemical performance tests related to the oxygen reduction reaction (ORR) were measured on the Pine Research Instrumentation, USA by using a three-electrode configuration in $0.1 \mathrm{M} \mathrm{KOH}$ solution. The rotating ring-disk electrode (RRDE) measurements are composed of a rotating disk electrode (glassy carbon disk, $5 \mathrm{~mm}$ in diameter), a rotating ring-disk electrode (glassy carbon disk, $6.5 \mathrm{~mm}$ inner diameter, Pt ring), graphitic carbon rod and 
$\mathrm{Ag} / \mathrm{AgCl}$ electrode (saturated $\mathrm{KCl}$ solution)) as the working, counter and reference electrode, respectively. The reference electrode, $\mathrm{Ag} / \mathrm{AgCl}$ (saturated $\mathrm{KCl}$ solution), was calibrated with respect to the reversible hydrogen electrode $(\mathrm{RHE}), \mathrm{E}_{\mathrm{RHE}}=\mathrm{E}_{\mathrm{Ag} / \mathrm{AgCl}}+0.059 \times \mathrm{pH}+0.1971$. All catalysts were prepared by mixing $4 \mathrm{mg}$ of obtained sample, $80 \mu \mathrm{l}$ of Nafion (5 wt \%) and $1 \mathrm{ml}$ solvent (1:1 v/v water/isopropanol) and then sonicated for $30 \mathrm{~min}$ to form a dispersion. $10 \mu \mathrm{l}$ of the dispersion was dropped onto the disk electrode, followed by drying at room temperature. The mass loading of the catalyst on the disk electrode is $0.20 \mathrm{mg} \mathrm{cm}^{-2}$.

The oxygen or nitrogen flow was delivered to the electrolyte for $30 \mathrm{~min}$ before the electrochemical measurement to achieve a saturated solution. The RDE measurement was conducted at various rotating speed (400 to $2000 \mathrm{rpm}$ ) with a sweep rate of $10 \mathrm{mV} \mathrm{s}^{-1}$. The cyclic voltammetry $(\mathrm{CV})$ measurements were performed by cycling with a scan rate of $100 \mathrm{mV}$ $\mathrm{s}^{-1}$.

The electron transfer number $(n)$ and kinetic current density $\left(J_{\mathrm{k}}\right)$ were calculated by the Koutecky-Levich equation:

$$
\begin{gathered}
\frac{1}{J}=\frac{1}{J_{L}}+\frac{1}{J_{K}}=\frac{1}{B \omega^{\frac{1}{2}}}+\frac{1}{J_{K}} \\
B=0.62 n F C_{0} D_{0}^{\frac{2}{3}} V^{-\frac{1}{6}}
\end{gathered}
$$

Where $J$ is the current density obtained from the ORR measurement, $J_{K}$ and $J_{L}$ are the kinetic and limiting current densities, $\mathrm{n}$ is the electron transfer number, $\omega$ is the angular velocity of the disk, $\mathrm{F}$ is the Faraday constant $\left(96485 \mathrm{C} \mathrm{mol}^{-1}\right), C_{0}$ is the bulk concentration of $\mathrm{O}_{2}\left(1.2 \times 10^{-6} \mathrm{~mol} \mathrm{~cm}^{-3}\right), D_{0}$ is the diffusion coefficient of $\mathrm{O}_{2}$ in $0.1 \mathrm{M} \mathrm{KOH}$ solution $\left(1.9 \times 10^{-}\right.$ $\left.{ }^{5} \mathrm{~cm}^{2} \mathrm{~s}^{-1}\right)$, and $V$ is the kinematic viscosity of the electrolyte $\left(0.01 \mathrm{~cm}^{2} \mathrm{~s}^{-1}\right)$.

The durability test were performed by repeating linear sweep voltammograms (LSV) for 5000 cycles (accelerated scan rate $50 \mathrm{mV} \mathrm{s}^{-1}$ ) with the potential range between 1.0 and $0.6 \mathrm{~V}$ vs. RHE.

For the Rotating-ring disk electrode tests, the disk electrode was scanned catholically with a scan rate of $10 \mathrm{mV} \mathrm{s}^{-1}$. Meanwhile, the potential for the ring electrode was $1.23 \mathrm{~V}$ vs. RHE, 
resulting in the electro-oxidation of $\mathrm{H}_{2} \mathrm{O}_{2}$. The hydrogen peroxide yield $\left(\mathrm{H}_{2} \mathrm{O}_{2}(\%)\right)$ and electron transfer number $(\mathrm{n})$ were calculated based on the following equations:

$$
\begin{gathered}
H_{2} O_{2}(\%)=200 \times \frac{\frac{I_{r}}{N}}{I_{d}+\frac{I_{r}}{N}} \\
n=4 \times \frac{I_{d}}{I_{d}+\frac{I_{r}}{N}}
\end{gathered}
$$

Where $I_{\mathrm{d}}$ is the disk current, $I_{\mathrm{r}}$ is the ring current and $N=0.4$ is the current collection efficiency of the platinum ring.

\section{Density Functional Theory (DFT) Calculations}

All calculation on $\mathrm{M}-\mathrm{SAs} / \mathrm{NSC}(\mathrm{M}=\mathrm{Fe}$, $\mathrm{Co} \mathrm{Ni})$ were conducted by Generalized Gradient Approximation (GGA) with the Perdew-Burke-Ernzerhof (PBE) exchange-correlation parameterization to Density Functional Theory (DFT) using CASTEP code. A $500 \mathrm{eV}$ cutoff for the plane-wave basis set were adopted in all computations, and meanwhile a $(2 \times 2 \times 1) \mathrm{k}$ point grid was applied. DFT Semi-core Pseudopots (DSPPs) was used to describe the interactions of valence electrons and ionic cores. The geometry optimization parameters of total energy convergence, max ionic force was $5 \times 10^{-6} \mathrm{eV}$ and $2 \times 10^{-5} \mathrm{eV} \AA^{-1}$, respectively. The Mulliken charge equation were applied to analysis the electronegativity of center metal atom. 


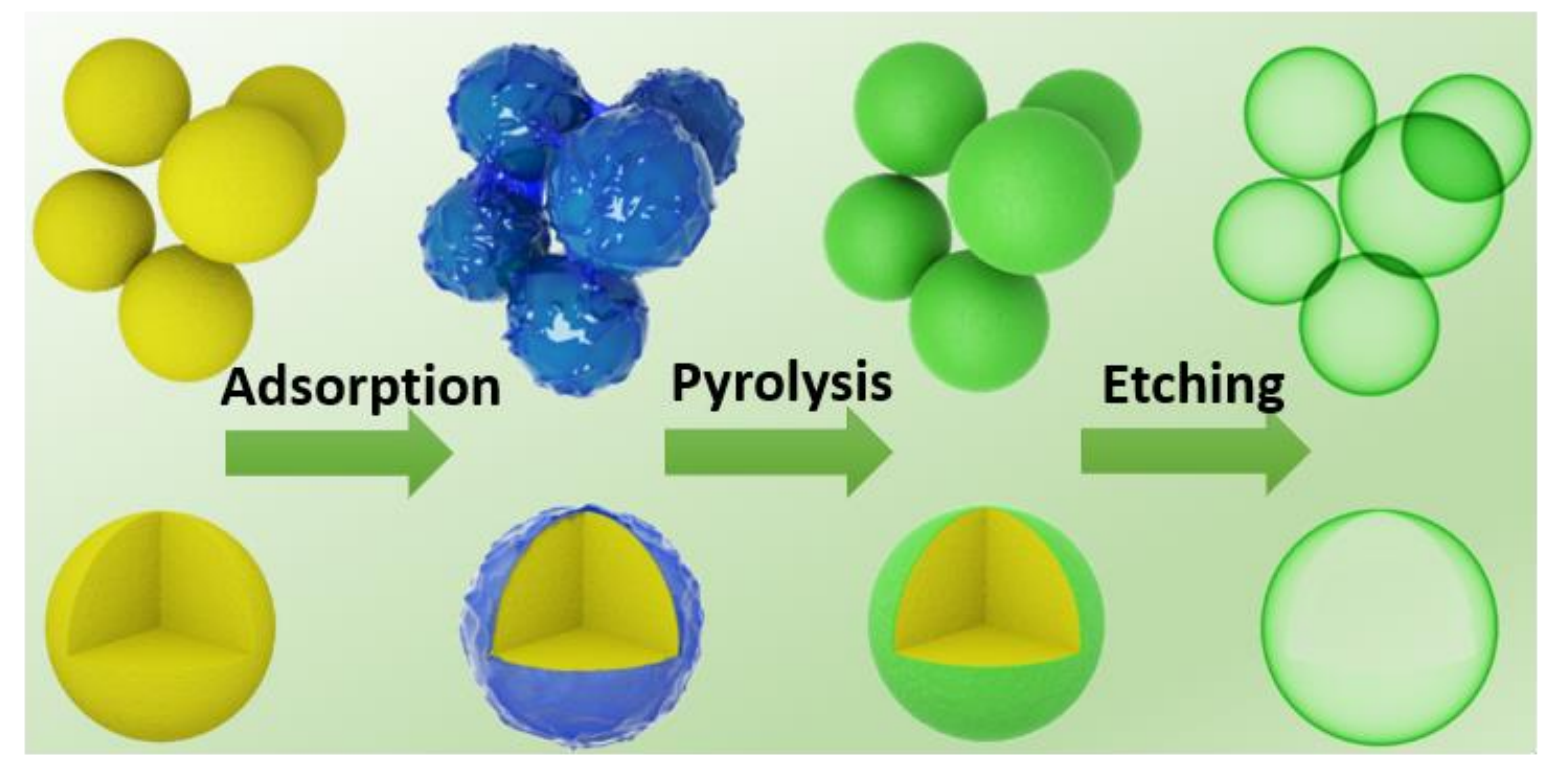

Figure S1. Schematic illustration of the synthesis process of the single-atom catalysts. 


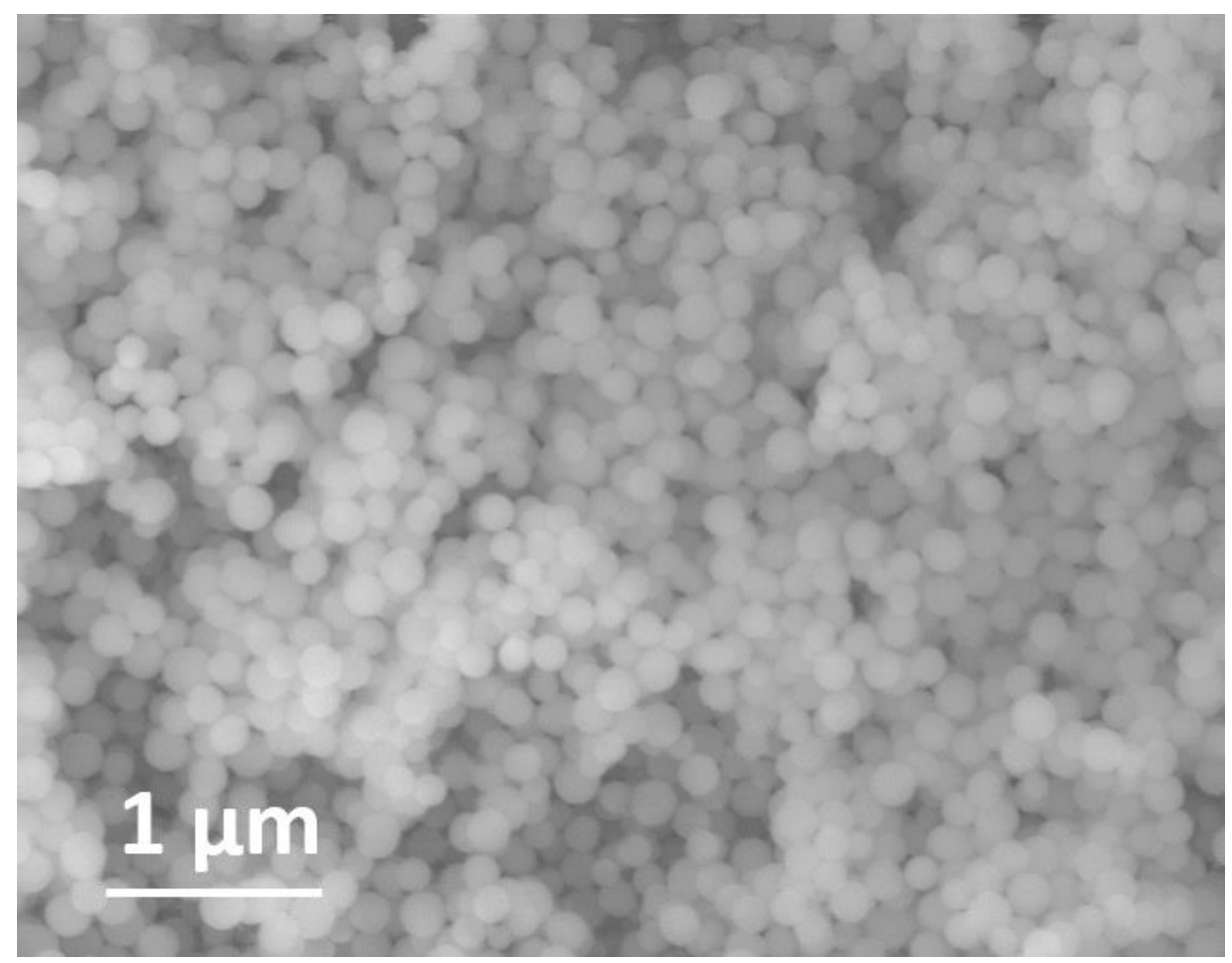

Figure S2. SEM image of the template $\mathrm{SiO}_{2}$. 


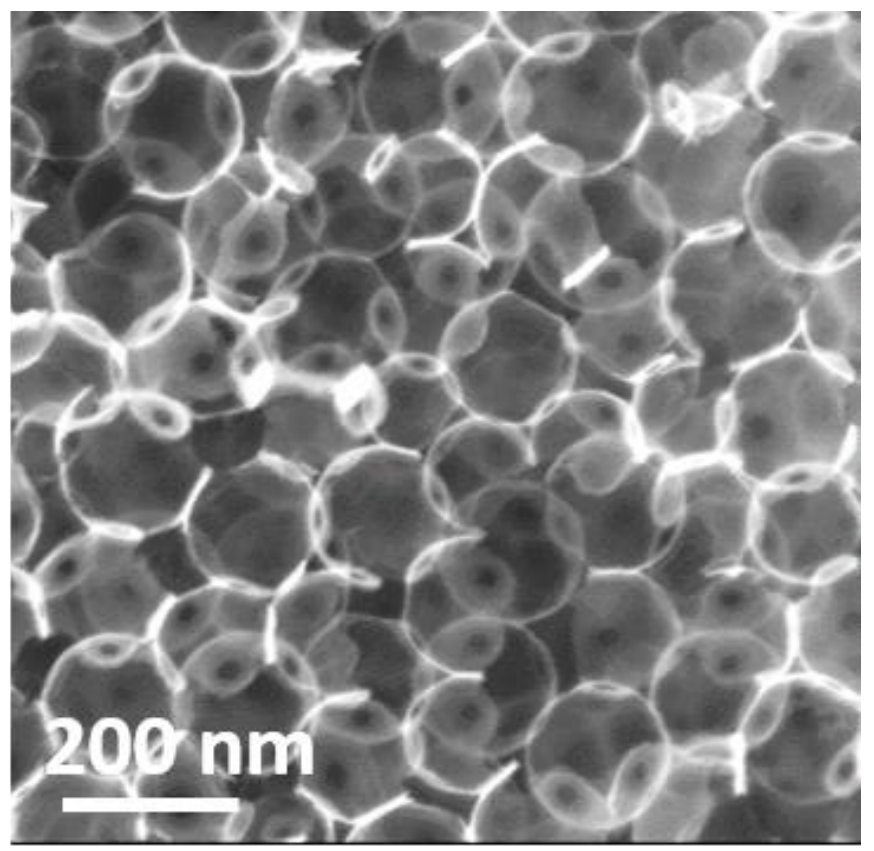

Figure S3. SEM image of Fe-SAs/NSC. 


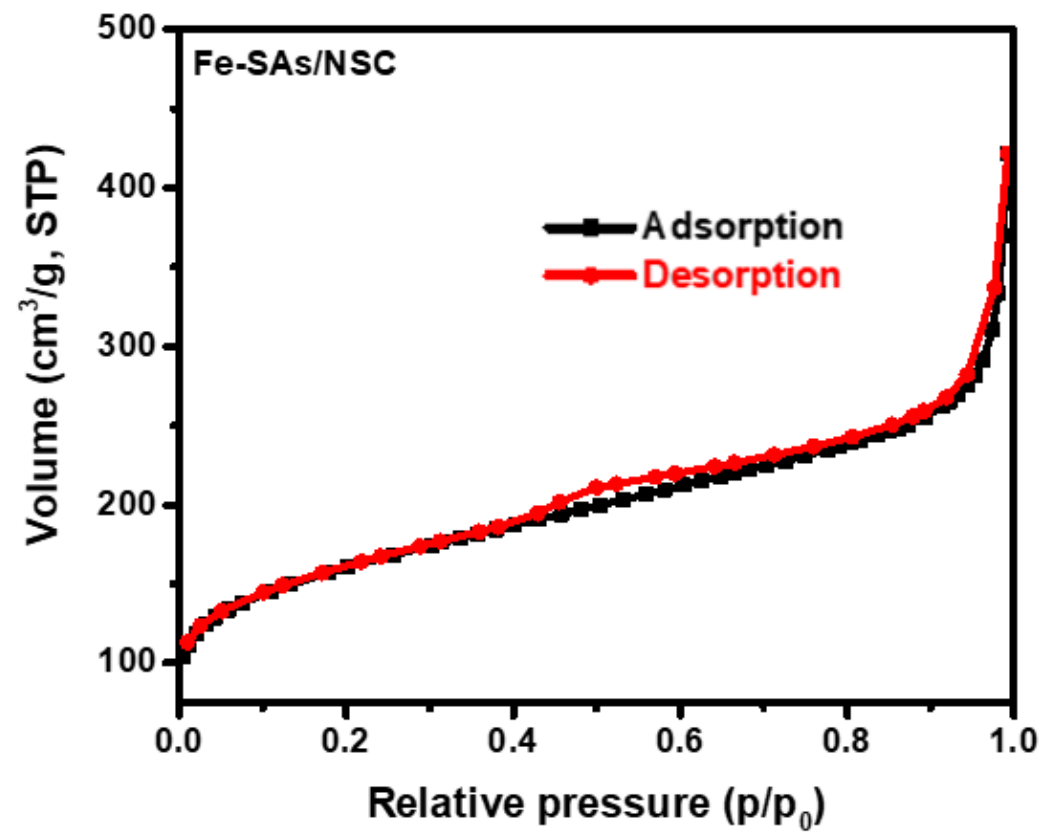

Figure S4. Nitrogen adsorption/desorption isotherm of Fe-SAs/NSC.

The BET surface of Fe-SAs/NSC is calculated as $547.6 \mathrm{~m}^{2} \mathrm{~g}^{-1}$. 

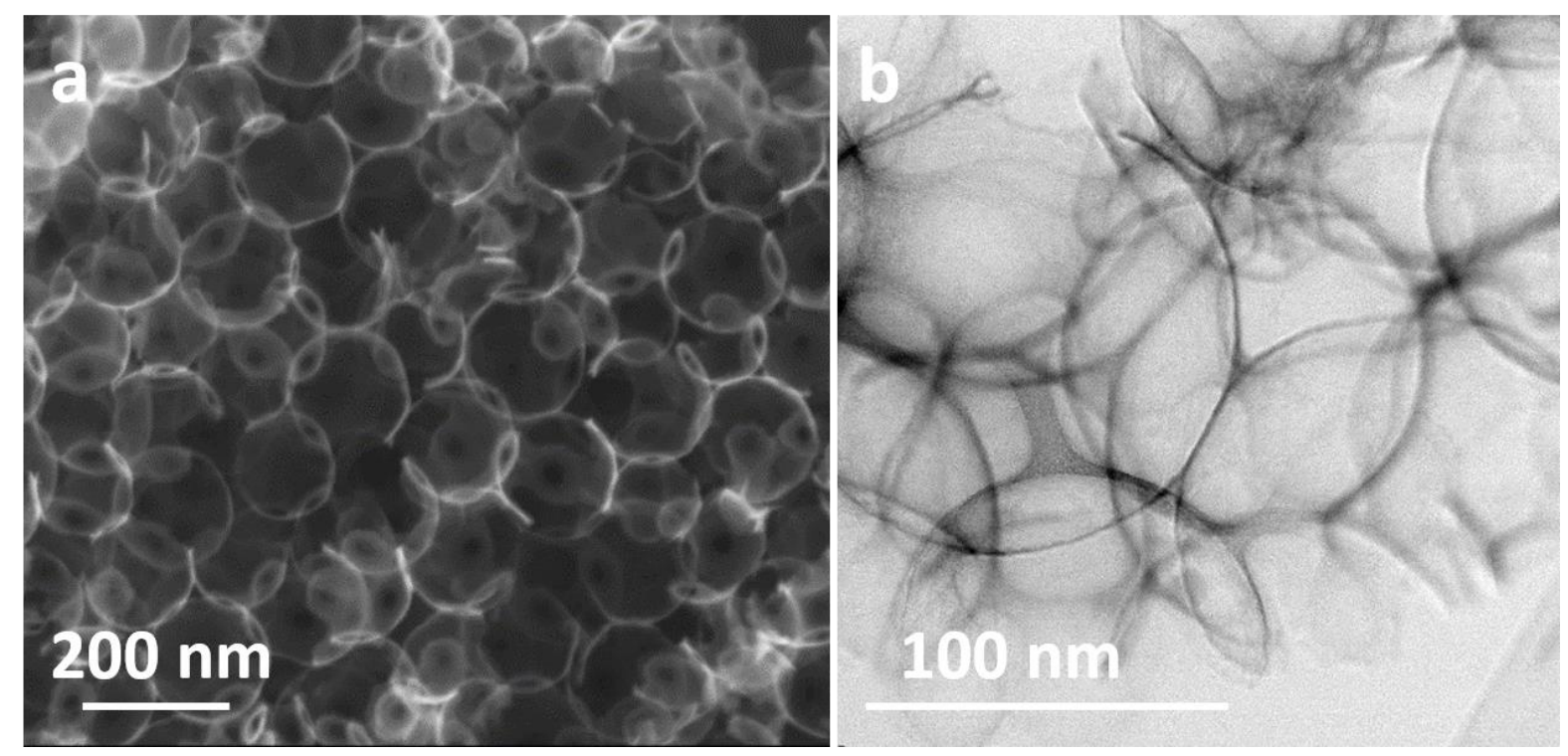

Figure S5. The SEM and TEM images of NSC. 


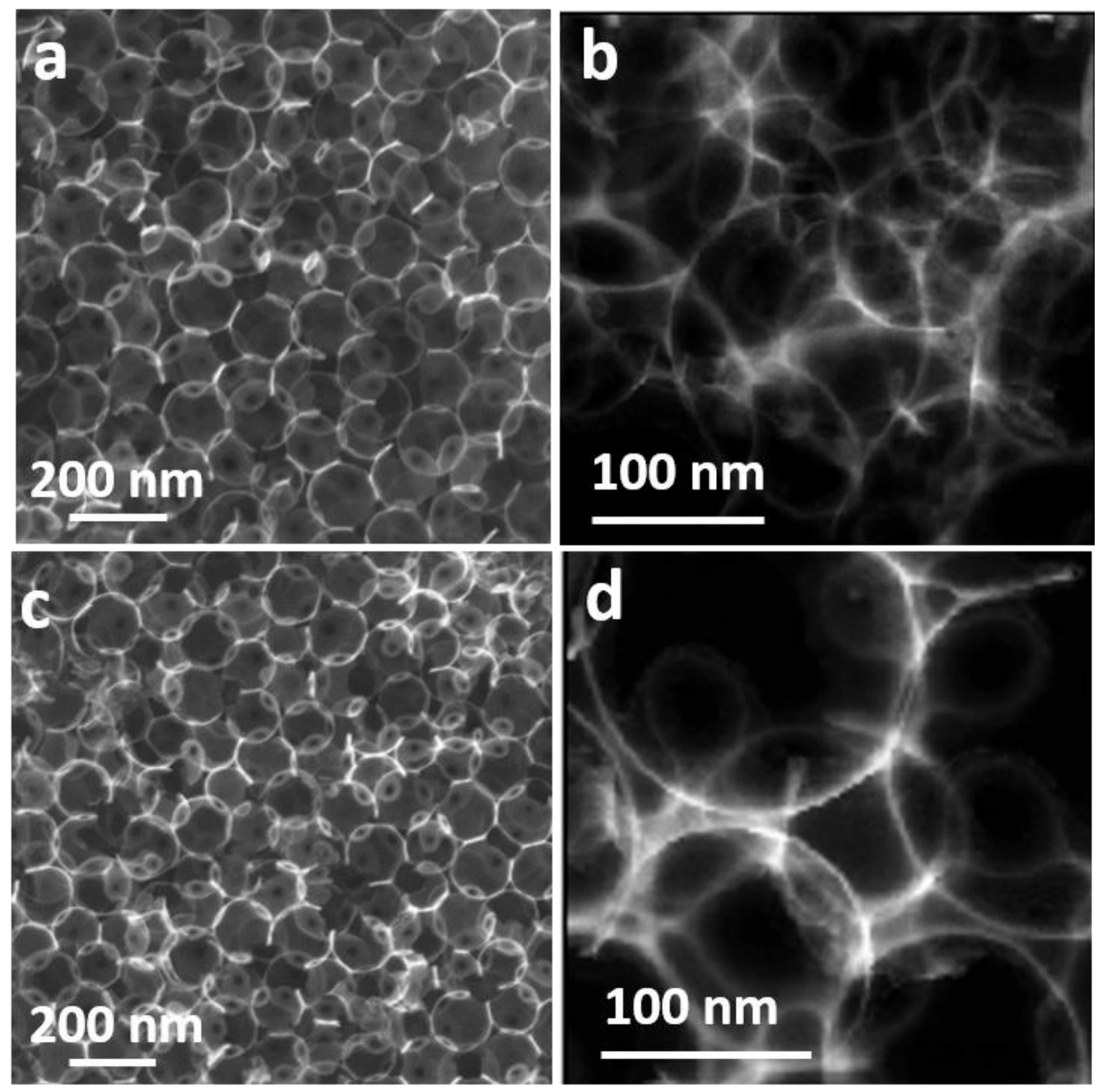

Figure S6. Morphology characterization of Co-SAs/NSC and Ni-SAs/NSC. (a, b) SEM and STEM images of Co-SAs/NSC, (c, d) SEM and STEM images of Ni-SAs/NSC.

The SEM and STEM images in Figure S6 show the porous structure of Co-SAs/NSC and NiSAs/NSC. No particles or clusters were observed on the entire carbon framework, suggesting that all $\mathrm{Co}$ and $\mathrm{Ni}$ species only exist as single atoms. The loading of the $\mathrm{Co}$ and $\mathrm{Ni}$ atoms on the carbon matrix was determined to be $0.90 \mathrm{wt} \%$ and $1.02 \mathrm{wt} \%$ by ICP-MS, respectively. 

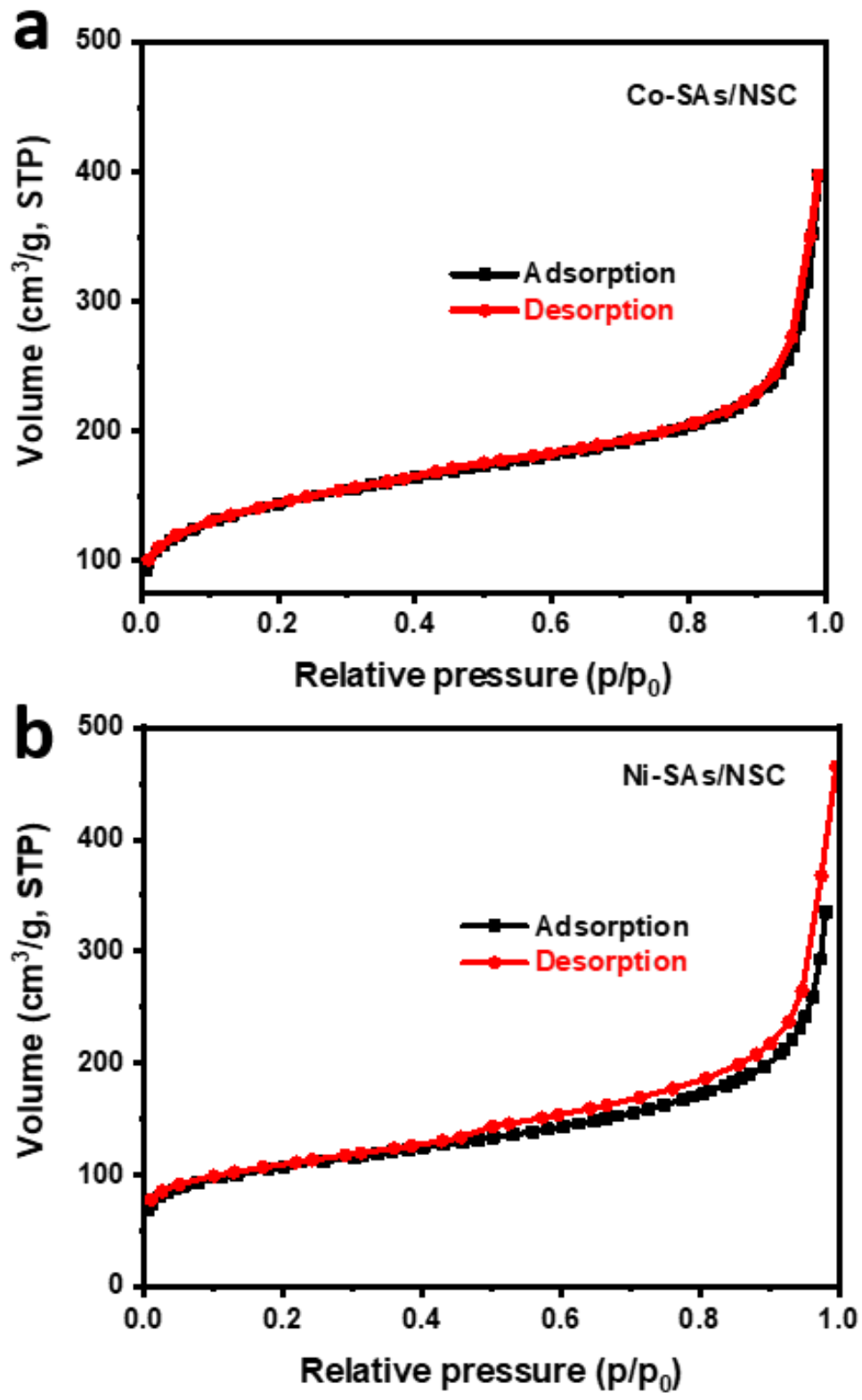

Figure S7. Nitrogen adsorption/desorption isotherm of (a) Co-SAs/NSC and (b) Ni-SAs/NSC. The BET surface area of Co-SAs/NSC is calculated as $488.9 \mathrm{~m}^{2} \mathrm{~g}^{-1}$ (Figure S7a) and $363.4 \mathrm{~m}^{2}$ $\mathrm{g}^{-1}$ for Ni-SAs/NSC (Figure S7b). 

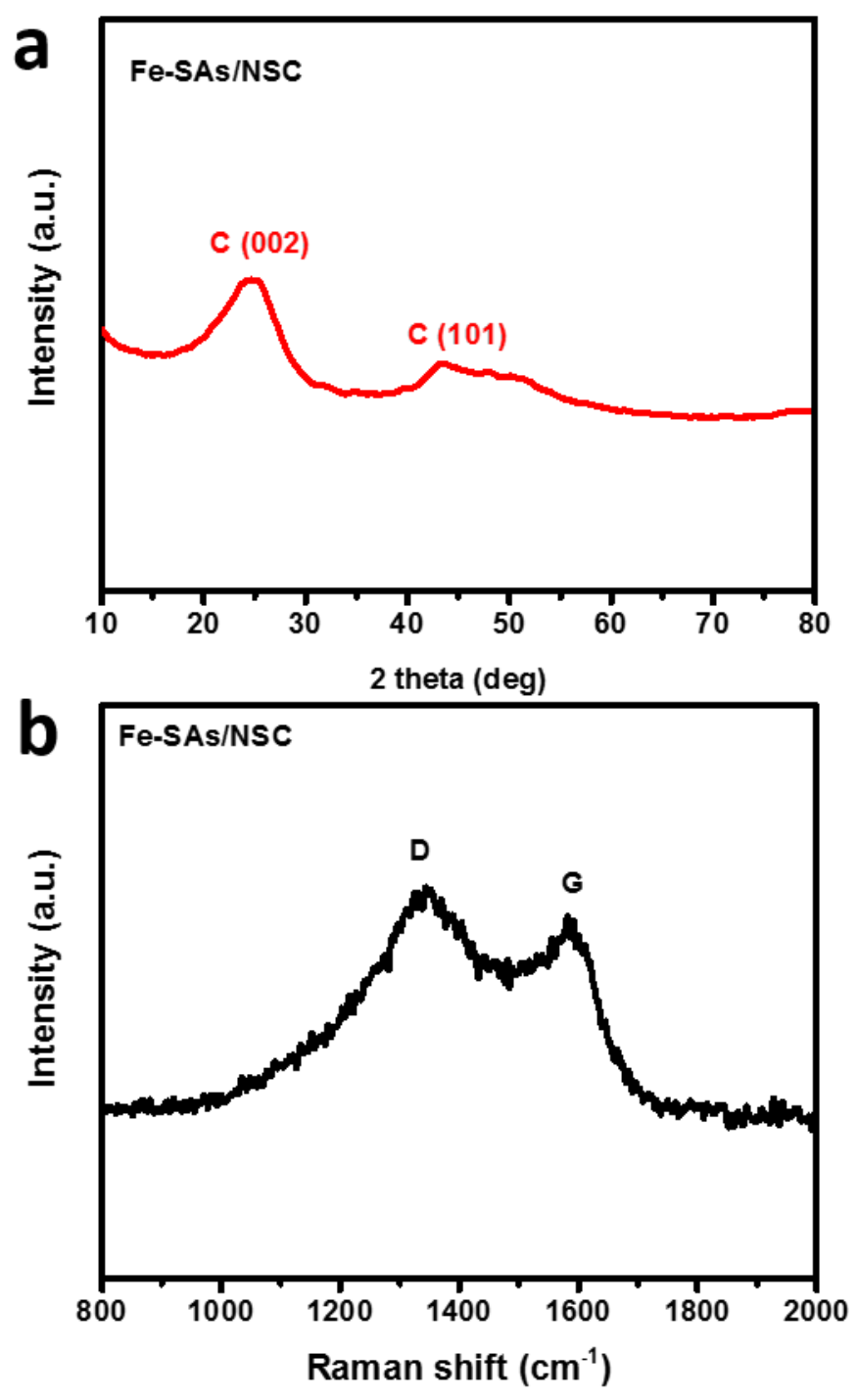

Figure S8. Structure characterization of Fe-SAs/NSC. (a) the XRD and (b) Raman spectra.

The XRD spectrum of the as-synthesized Fe-SAs/NSC catalysts in Figure S8a show only two main diffraction peaks at around 26 and $44^{\circ}$, attributing to the (002) and (101) planes of the graphitic carbon. And no more peaks are observed for Fe-related species, demonstrating the absence of Fe-related particles. And the Raman spectrum of Fe-SAs/NSC shows that the value of $\mathrm{I}_{\mathrm{D}} / \mathrm{I}_{\mathrm{G}}$ is 1.15 . 

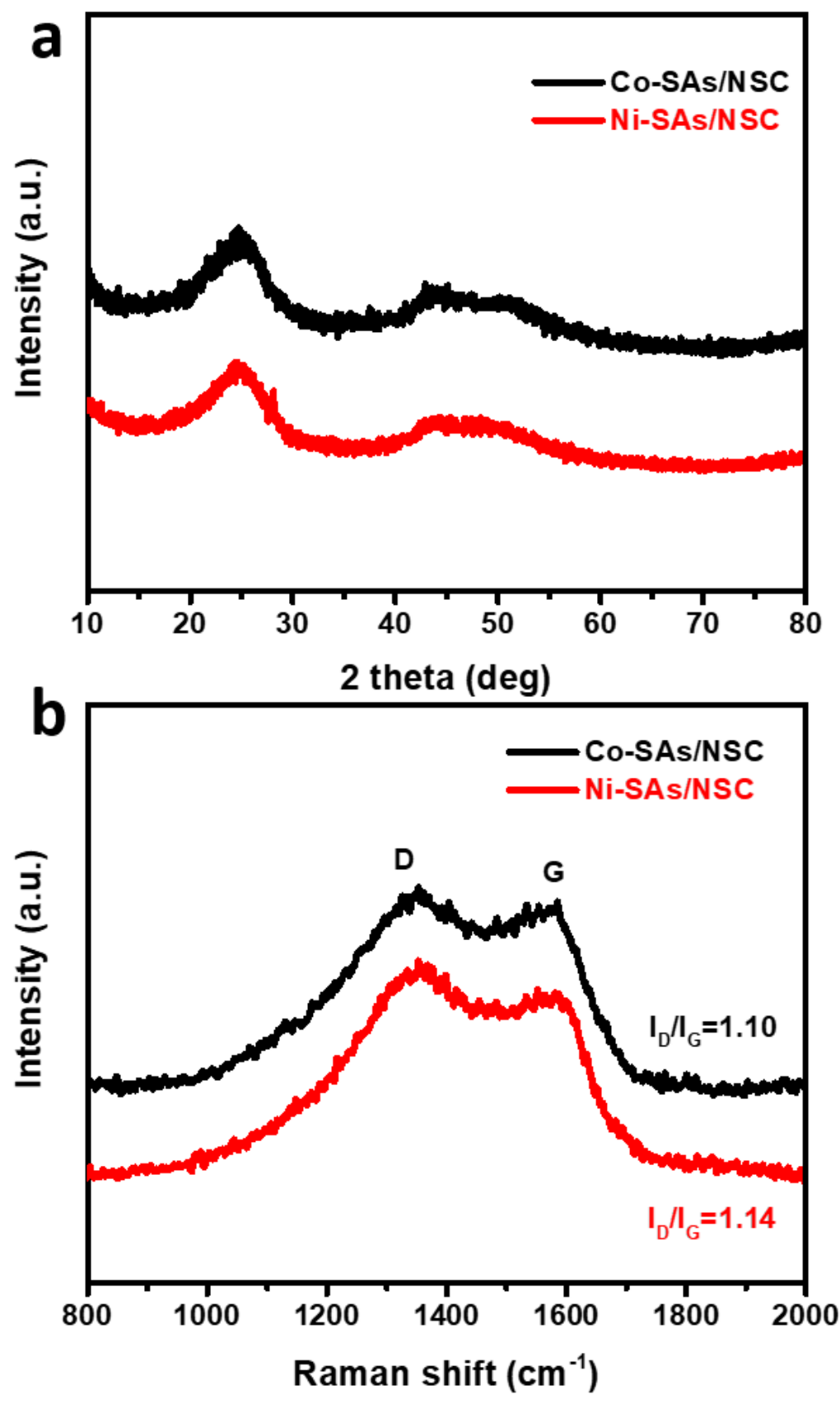

Figure S9. Structure characterization of Co-SAs/NSC and Ni-SAs/NSC. (a) the XRD and (b) Raman spectra of Co-SAs/NSC and Ni-SAs/NSC.

The XRD spectra of the as-synthesized Co-SAs/NSC and Ni-SAs/NSC catalysts in Figure S9a show only two main diffraction peaks at around 26 and $44^{\circ}$, attributing to the (002) and (101) planes of the graphitic carbon. And no more peaks are observed for metal-related species, demonstrating the absence of Co or Ni-related particles. The Raman spectra of Co-SAs/NSC and Ni-SAs/NSC in Figure S9b exhibit the intensity between D band to G band are 1.10 and 1.14 , respectively. 

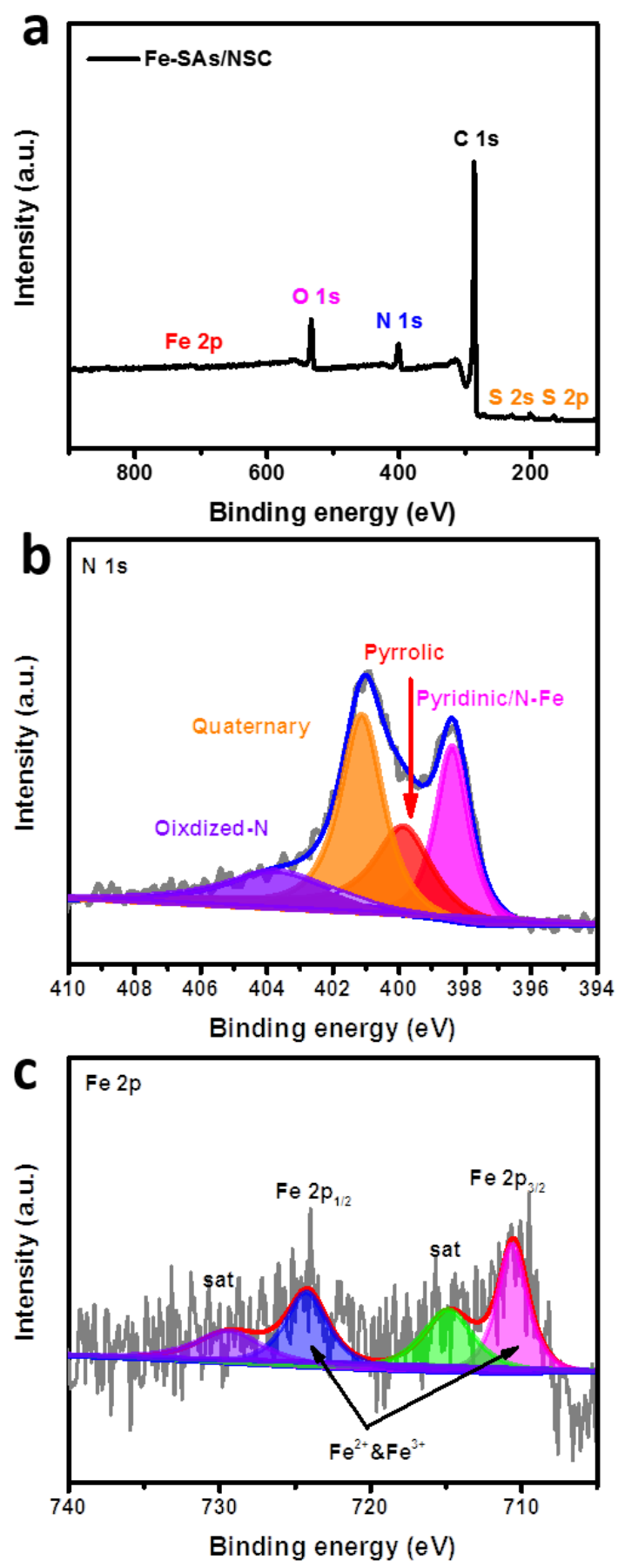

Figure S10. The XPS spectra of Fe-SAs/NSC. (a) XPS survey of Fe-SAs/NSC, (b) the high resolution of $\mathrm{N} \mathrm{1s,} \mathrm{(c)} \mathrm{the} \mathrm{high} \mathrm{resolution} \mathrm{of} \mathrm{Fe} \mathrm{2p.}$

The XPS survey result reveals that Fe-SAs/NSC is composed of Fe, O, N, C, S and no other impurities are observed, which is consistent with the result of STEM mapping. The high resolution spectrum of $\mathrm{Fe} 2 \mathrm{p}$ in Figure $\mathrm{S} 10 \mathrm{c}$ shows that the binding energies of Fe $2 \mathrm{p}$ are 724.3 and $710.6 \mathrm{eV}$, which is higher than that of $\mathrm{Fe}(0)(719.7$ and $707.4 \mathrm{eV}) .{ }^{1}$ This indicates the formation of $\mathrm{Fe}$ at their oxidation state. 

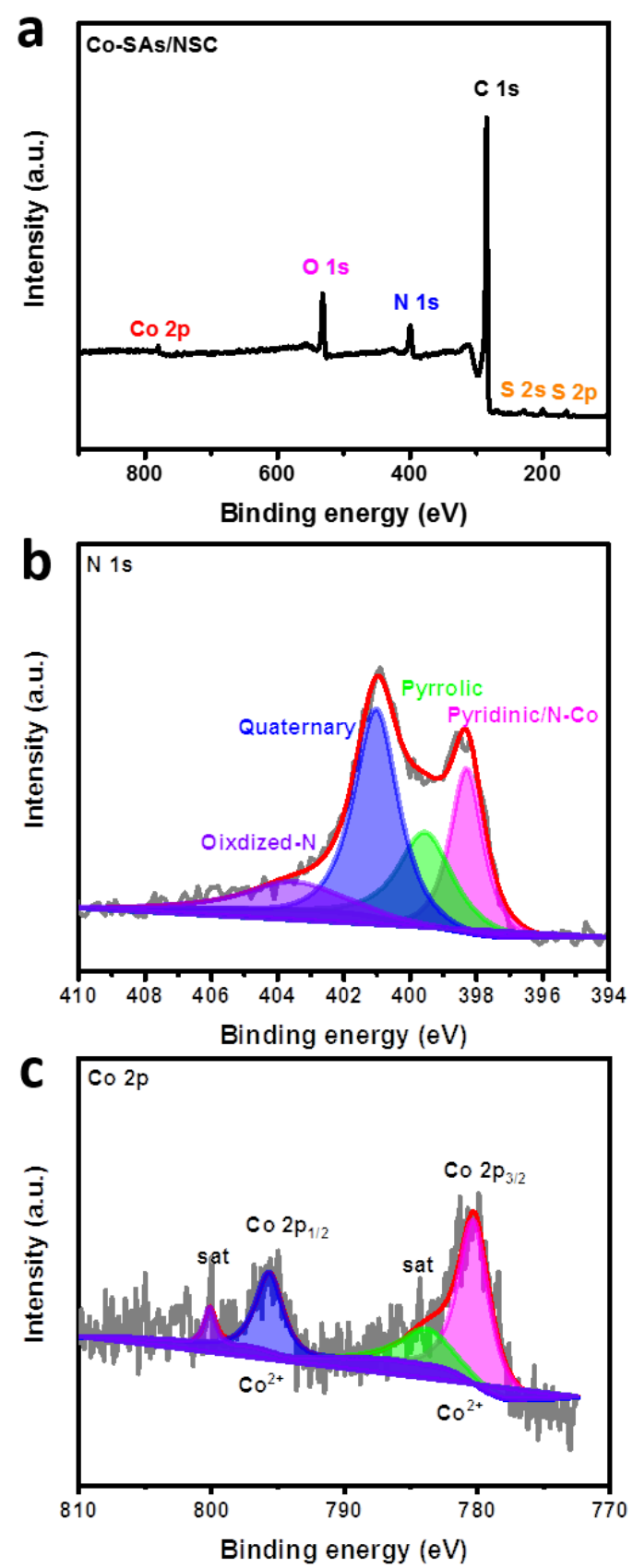

Figure S11. The XPS spectra of Co-SAs/NSC. (a) XPS survey of Co-SAs/NSC, (b) the high resolution of $\mathrm{N} \mathrm{1s,} \mathrm{(c)} \mathrm{the} \mathrm{high} \mathrm{resolution} \mathrm{of} \mathrm{Co} 2 \mathrm{p}$.

The XPS survey result in Figure S11a reveals that Co-SAs/NSC is composed of Co, O, N, C, $\mathrm{S}$ and no other impurities are observed. The high resolution $\mathrm{N}$ 1s of Co-SAs/NSC in Figure $\mathrm{S} 11 \mathrm{~b}$ confirm the existence of $\mathrm{C}-\mathrm{N}$ and $\mathrm{Co}-\mathrm{N}$ bonds. The high resolution spectrum of Co $2 \mathrm{p}$ in Figure S11c shows that the binding energies of Co $2 \mathrm{p}$ are 795.5 and $780.4 \mathrm{eV}$, which is higher than that of $\operatorname{Co}(0)(794.7$ and $779.2 \mathrm{eV}) .{ }^{2}$ This indicates the formation of $\mathrm{Co}$ at their oxidation state. 

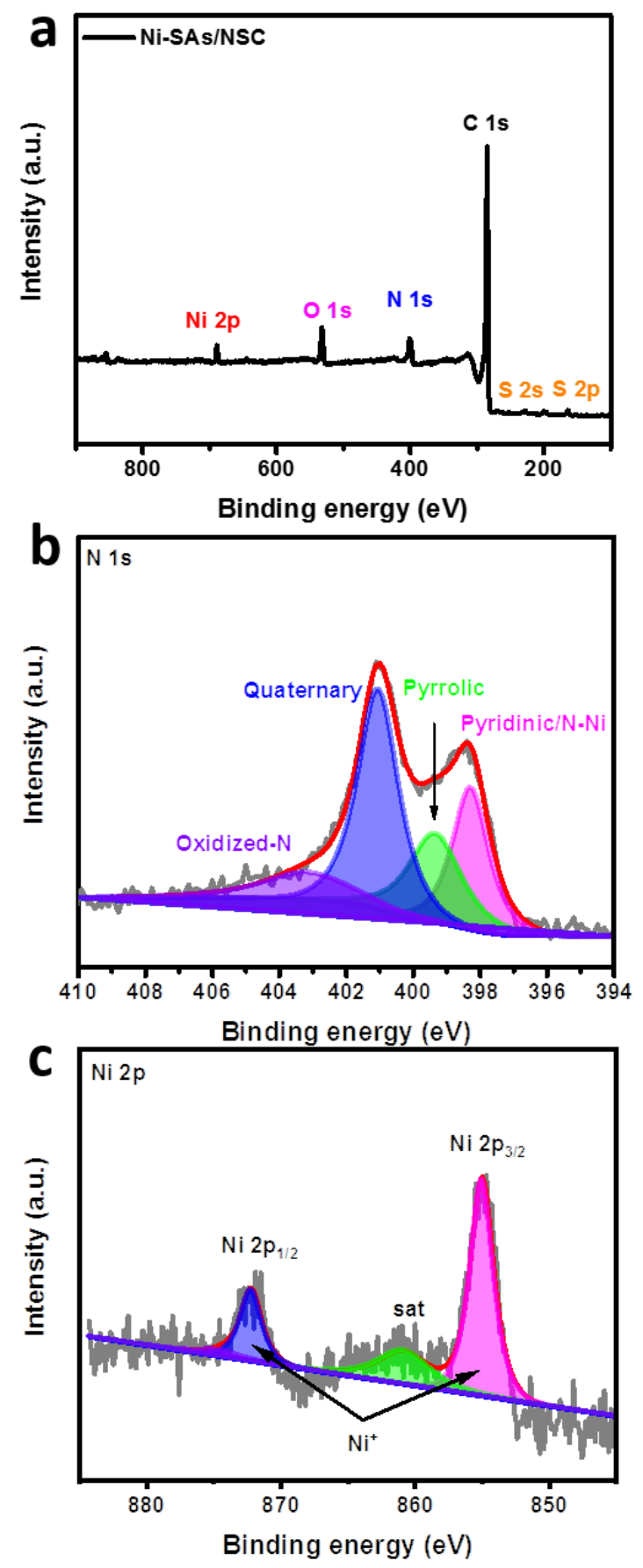

Figure S12. The XPS spectra of Ni-SAs/NSC. (a) XPS survey of Ni-SAs/NSC, (b) the high resolution of $\mathrm{N} \mathrm{1s,} \mathrm{(c)} \mathrm{the} \mathrm{high} \mathrm{resolution} \mathrm{of} \mathrm{Ni} 2 \mathrm{p}$.

The XPS survey result in Figure S12a reveals that Ni-SAs/NSC is composed of Ni, O, N, C, S and no other impurities are observed. The high resolution $\mathrm{N}$ 1s of Ni-SAs/NSC in Figure S12b confirm the existence of $\mathrm{C}-\mathrm{N}$ and $\mathrm{Ni}-\mathrm{N}$ bonds. The high resolution spectrum of $\mathrm{Ni} 2 \mathrm{p}$ in Figure S12c shows that the binding energies of Ni $2 p$ are 872.3 and $855.0 \mathrm{eV}$, which is higher than that of $\mathrm{Ni}(0)(870.2$ and $852.8 \mathrm{eV}) .{ }^{3-4}$ This indicates the formation of $\mathrm{Ni}$ at their oxidation state. 

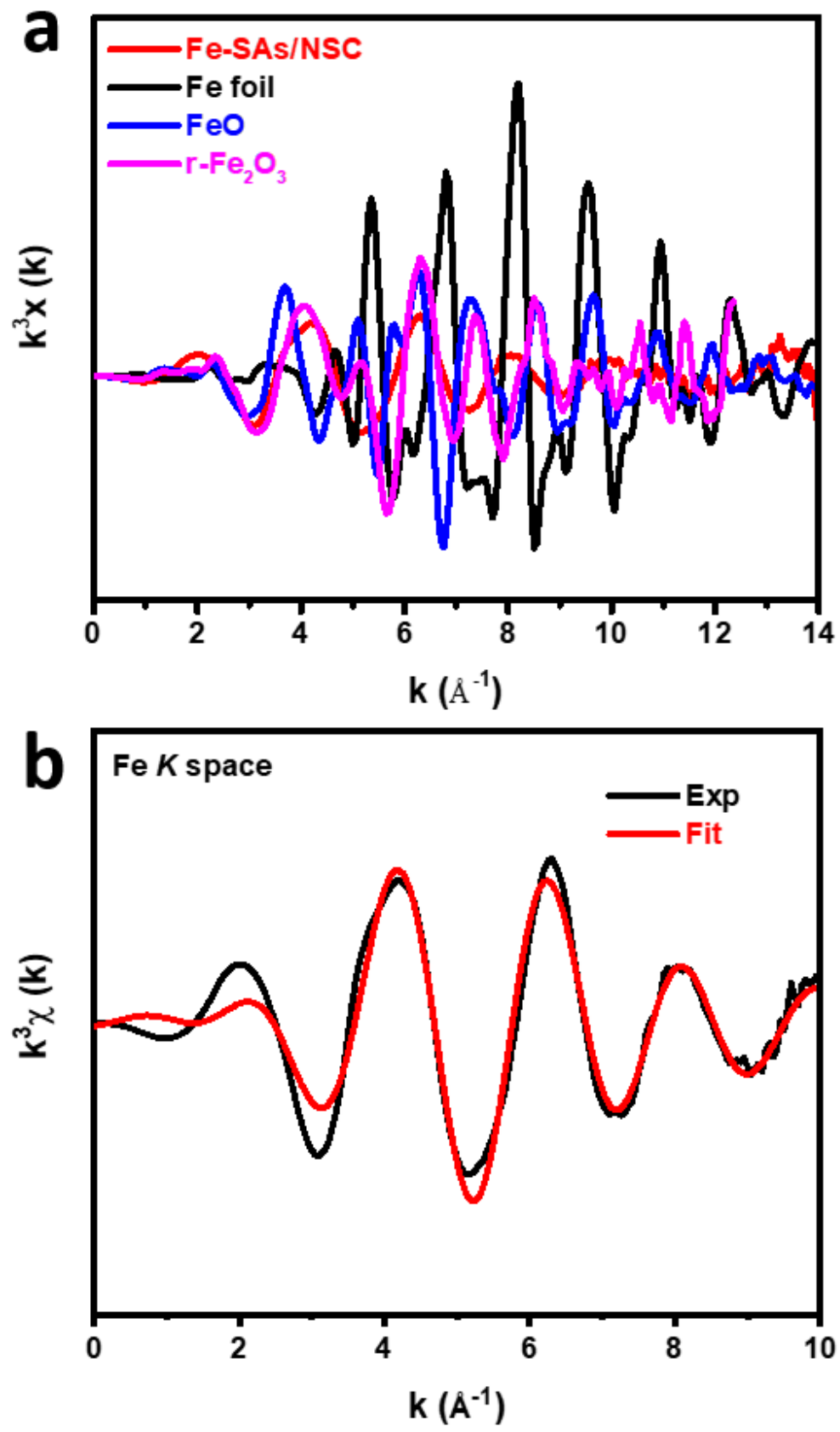

Figure S13. (a) The $k^{3}$-weighted EXAFS in $K$-space for Fe-SAs/NSC, Fe foil, $\mathrm{FeO}$ and $r-\mathrm{Fe}_{2} \mathrm{O}_{3}$, (b) Fe $K$-space fitting curve of Fe-SAs/NSC. 

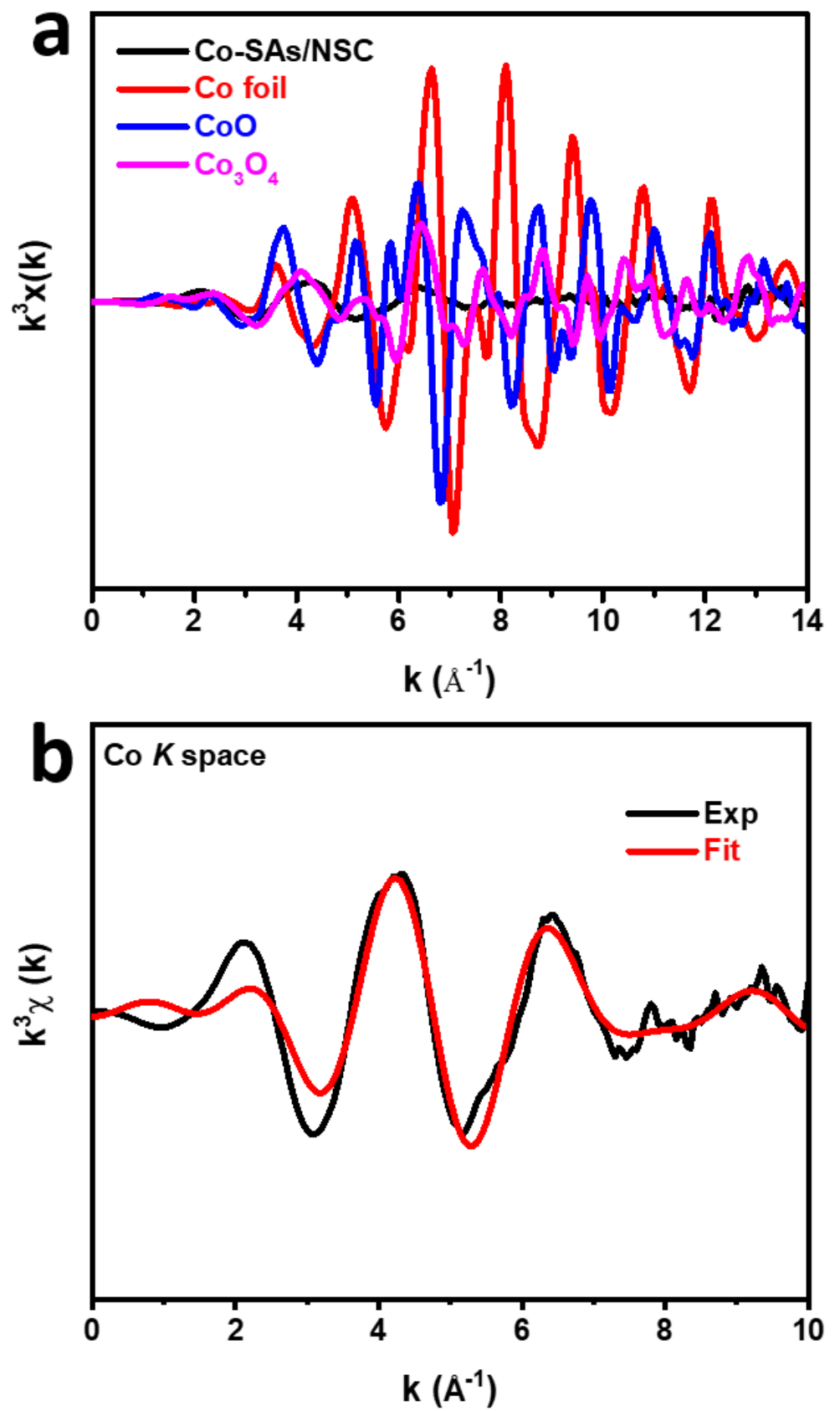

Figure S14. (a) The $k^{3}$-weighted EXAFS in $K$-space for Co-SAs/NSC, Co foil, $\mathrm{CoO}$ and $\mathrm{Co}_{3} \mathrm{O}_{4}$, (b) Co $K$-space fitting curve of Co-SAs/NSC. 

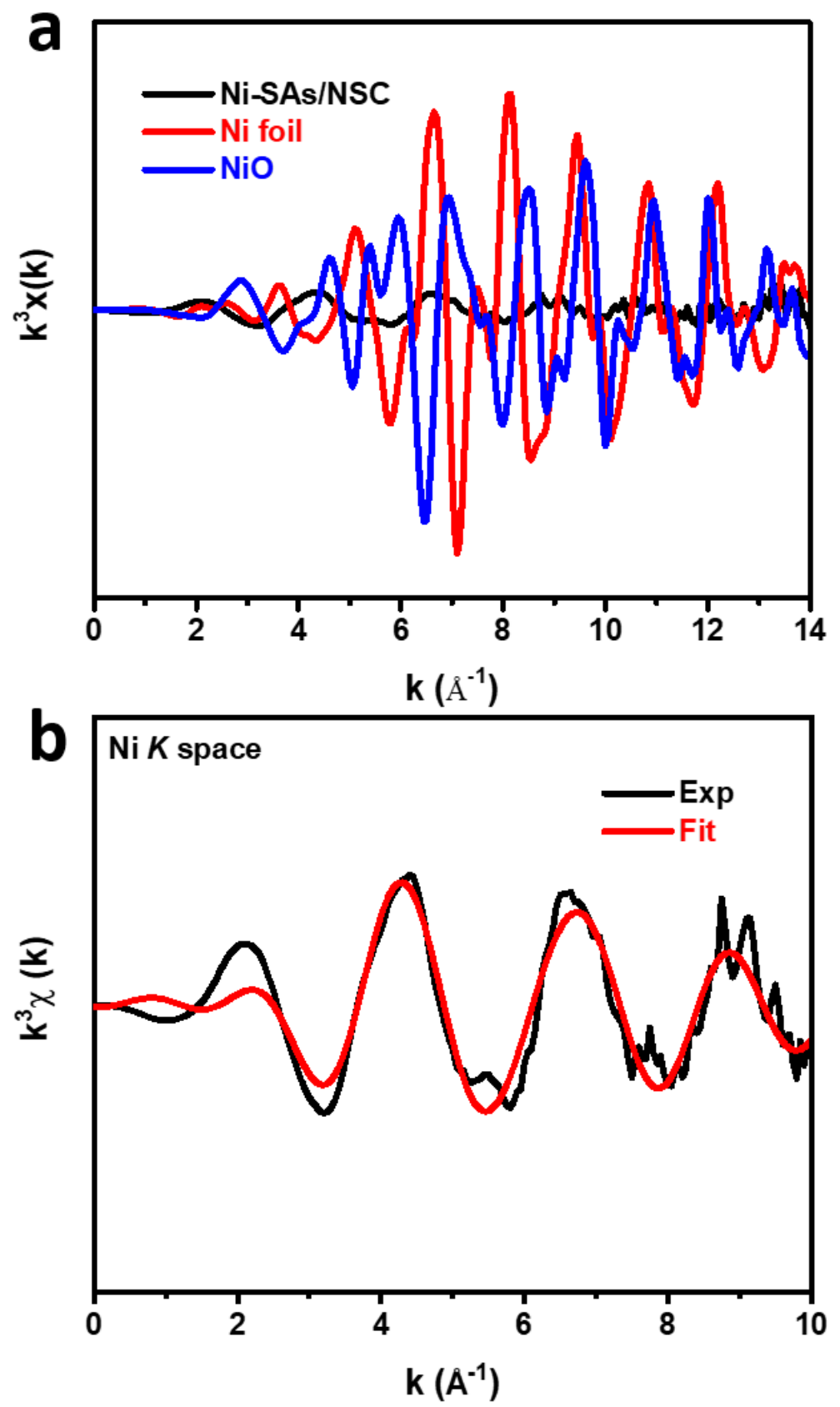

Figure S15. (a) The $k^{3}$-weighted EXAFS in $K$-space for Ni-SAs/NSC, Ni foil, and NiO, (b) Ni $K$-space fitting curve of Ni-SAs/NSC. 


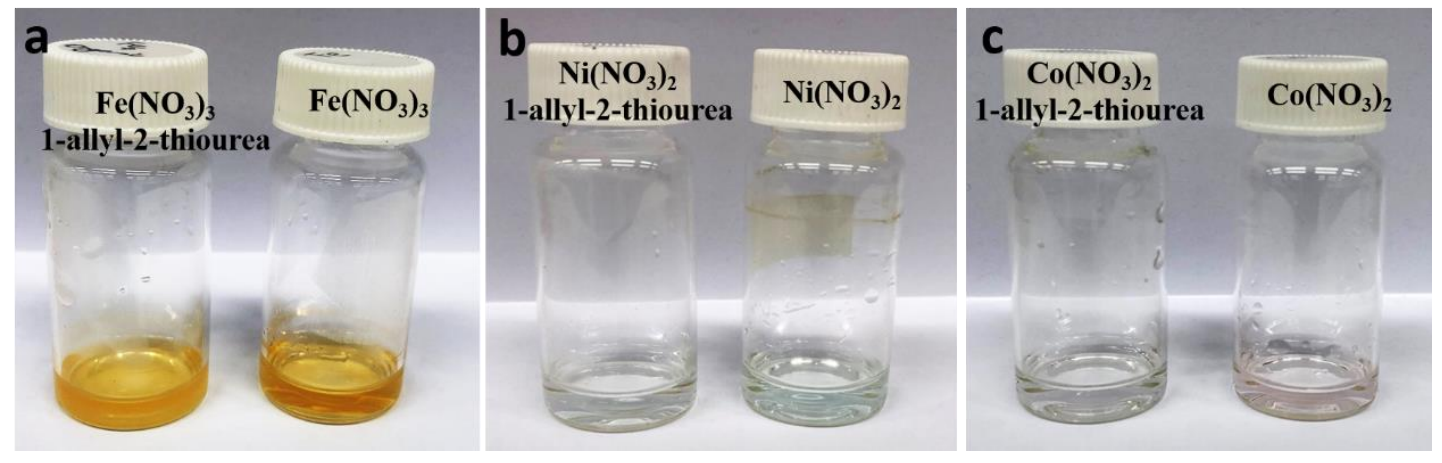

Figure S16. The photographs of the complexes. (a) The mixture of $\mathrm{Fe}\left(\mathrm{NO}_{3}\right)_{3}$ and 1-allyl-2thiourea, (b) $\mathrm{Co}\left(\mathrm{NO}_{3}\right)_{2}$ and 1-allyl-2-thiourea, and (c) $\mathrm{Ni}\left(\mathrm{NO}_{3}\right)_{2}$ and 1-allyl-2-thiourea comparing to the ones without the addition of organic molecules.

As displayed in Figure S16, the appearance of the solution slightly changed after the addition of 1-allyl-2-thiourea organic precursor. The clear orange $\mathrm{Fe}\left(\mathrm{NO}_{3}\right)_{3}$ solution turned suspension after the addition of 1-allyl-2-thiourea. And the colours of the $\mathrm{Ni}\left(\mathrm{NO}_{3}\right)_{2}$ and $\mathrm{Co}\left(\mathrm{NO}_{3}\right)_{2}$ solution faded slightly with the introduction of the organic precursor. The phenomenon provides evidence that the soluble metal ions are possibly coordinated by the organic precursors in the solution, which changes the composition and appearances of the solutions. 

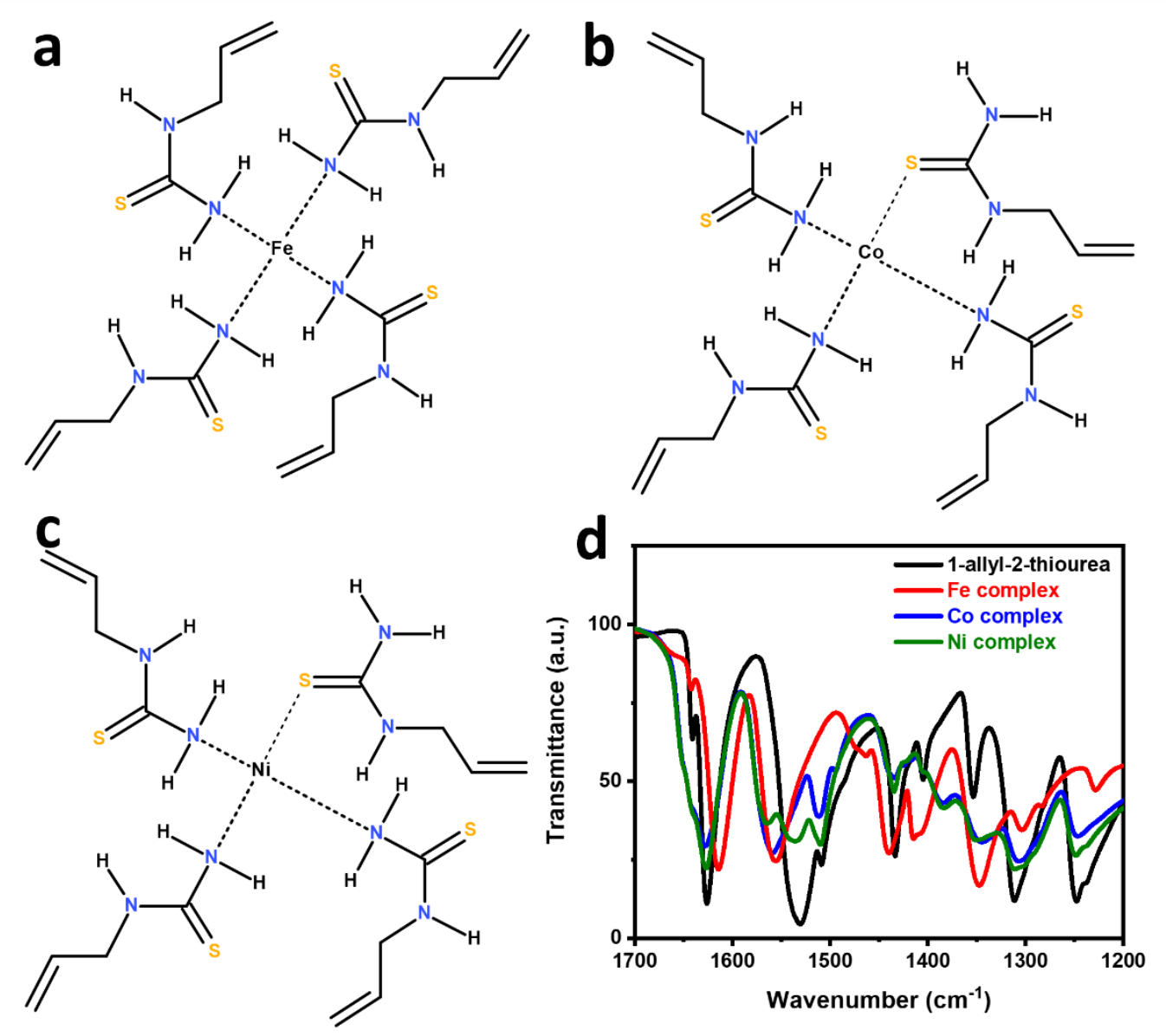

Figure S17. The proposed relatively stable intermediates after adding (a) $\mathrm{Fe}\left(\mathrm{NO}_{3}\right)_{3}$, (b) $\mathrm{Co}\left(\mathrm{NO}_{3}\right)_{2}$ and (c) $\mathrm{Ni}\left(\mathrm{NO}_{3}\right)_{2}$ in the carbon precursor (1-allyl-2-thiourea), and (d) FTIR spectra of the intermediates.

The characteristic FTIR peaks of 1-allyl-2-thiourea shift after added to the metal ion solution, referring to the alteration of the corresponding bonding environment of $\mathrm{N}-\mathrm{H}, \mathrm{N}-\mathrm{C}$, and $\mathrm{C}=\mathrm{S}$ bonds. This indicates that the organic precursor is coordinating with the centre metal ions to form complex intermediates. Intriguingly, the peak shifts of Fe complex are different from the ones of $\mathrm{Co}$ and $\mathrm{Ni}$ complexes, indicating two distinguishingly different bonding environments between $\mathrm{Fe}$ complex and $\mathrm{Co} / \mathrm{Ni}$ complexes. 

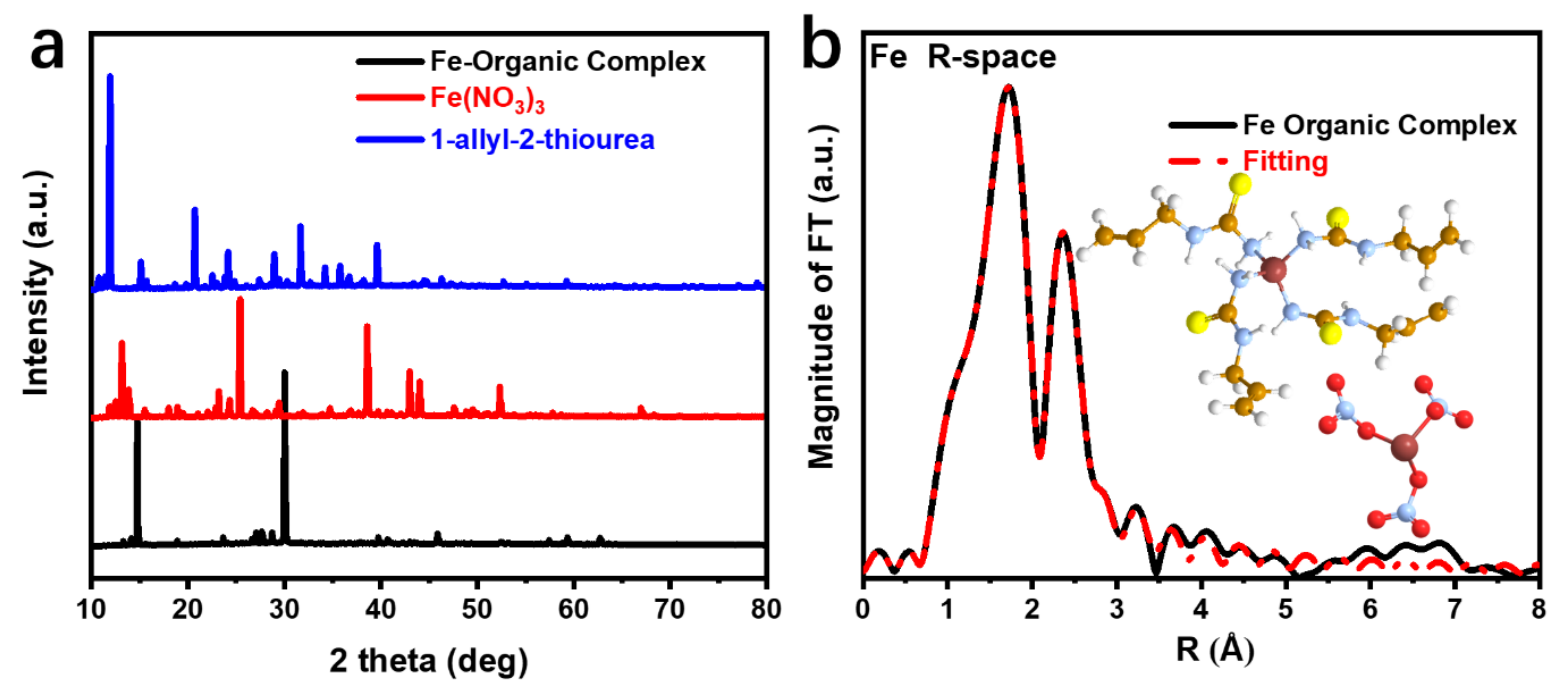

Figure S18. (a) XRD patterns of the Fe-organic complex precursor and (b) EXAFS curves between the experimental data and the fit of Fe-organic complex precursor. The insets are the fitted structures mixture of $\mathrm{Fe}(1 \text {-allyl-2-thiourea })_{4}$ and $\mathrm{Fe}\left(\mathrm{NO}_{3}\right)_{3}$.

The XRD patterns change after the mixing process, indicating that Fe ions form complex with 1-allyl-2-thiourea. Figure S18b confirms that there are no Fe-S bonds formed in the Fe-organic complex precursor. Furthermore, $4 \mathrm{Fe}-\mathrm{N}$ bonds are found in the bonding environment, originated from the complex legend 1-allyl-2-thiourea. The additional Fe-O bonds should be assigned to the residue $\mathrm{Fe}\left(\mathrm{NO}_{3}\right)_{3}$. The Fe-species may stack together to give Fe-Fe signal after drying. Therefore, the EXAFS result has confirmed the centre structure of the Fe-organic precursor, which was preserved after pyrolysis to give $\mathrm{FeN}_{4} \mathrm{~S}_{2}$ centre structure in Fe-SAs/NSC. 

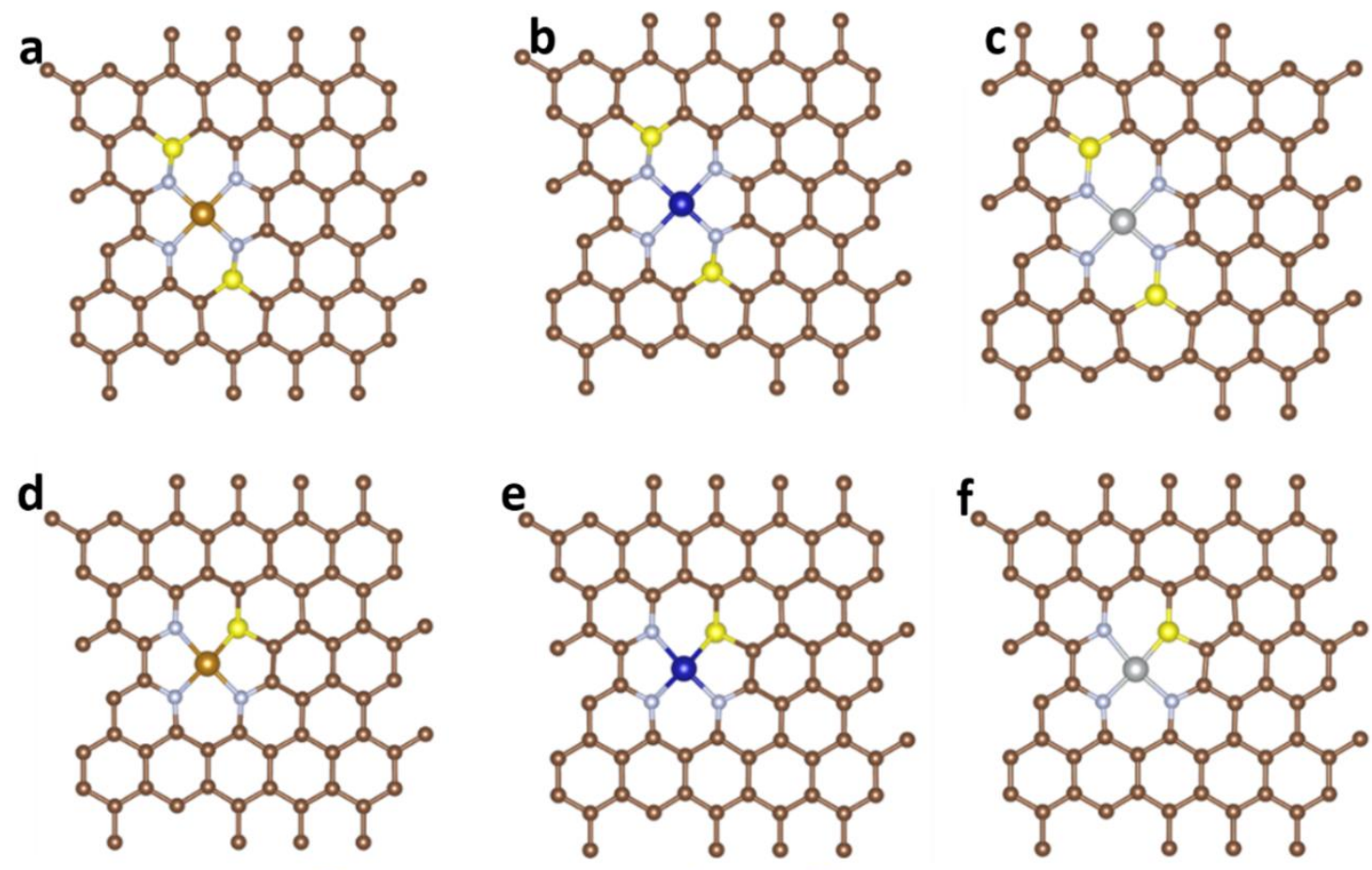

- Fe $\odot \mathrm{C}$
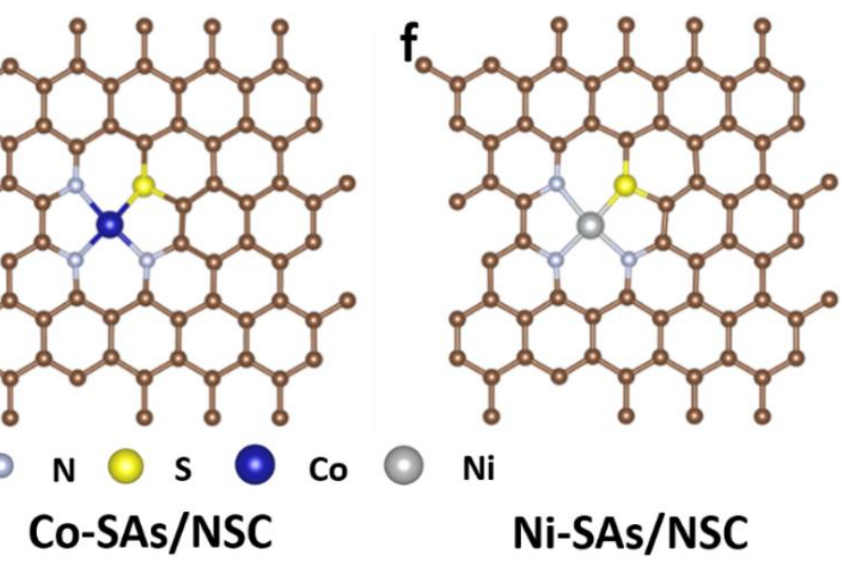

Fe-SAs/NSC Co-SAs/NSC

Ni-SAs/NSC

Figure S19. DFT models used for the stability calculations. The top view of the models used to describe (a, d) Fe-SAs/NSC, (b, e) Co-SAs/NSC, (c, f) Ni-SAs/NSC. (C: brown, N: light blue, S: yellow, Fe, dark brown, Co: blue, Ni: grey). 

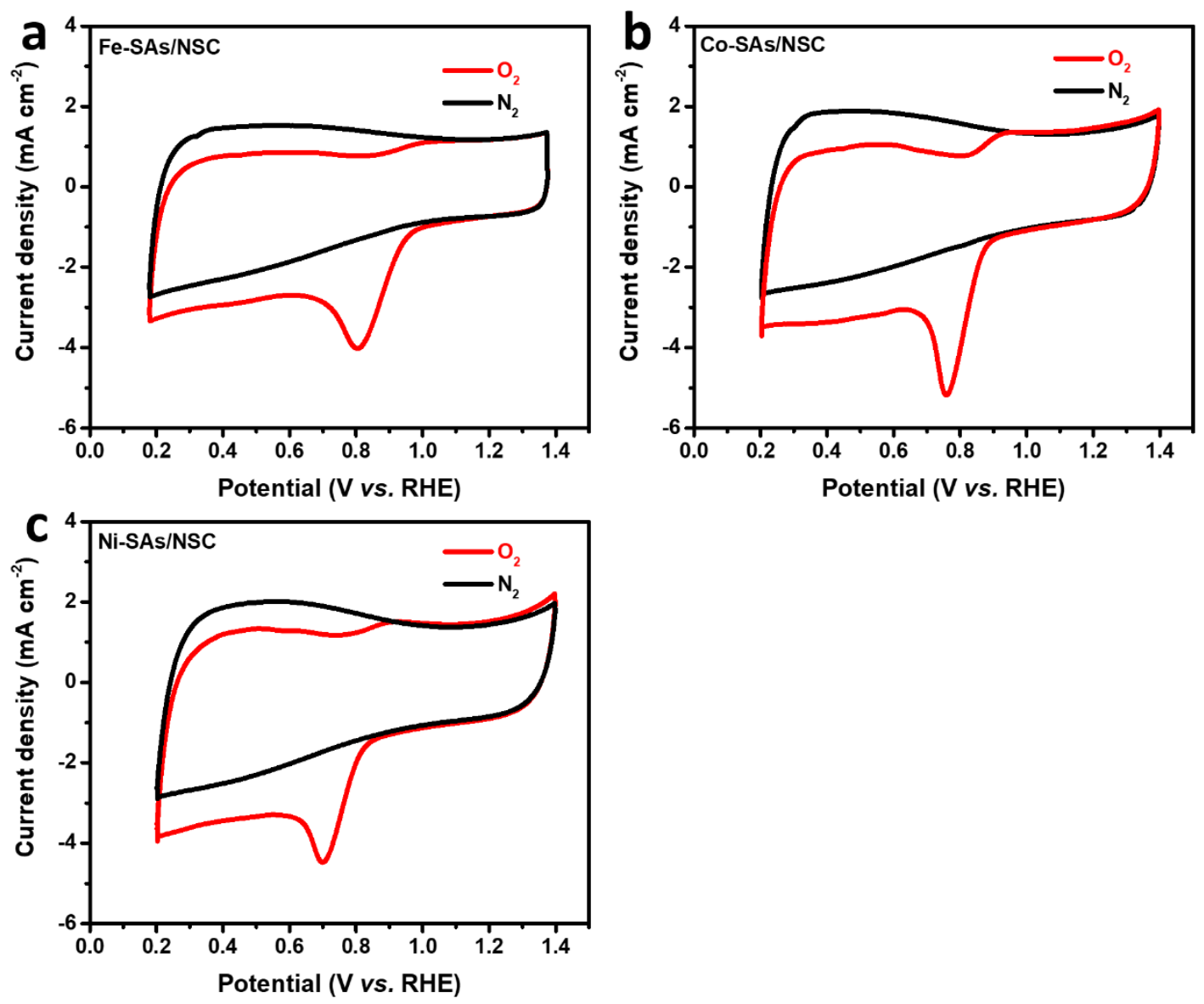

Figure S20. The CV curves of (a) Fe-SAs/NSC, (b) Co-SAs/NSC and (c) Ni-SAs/NSC. 


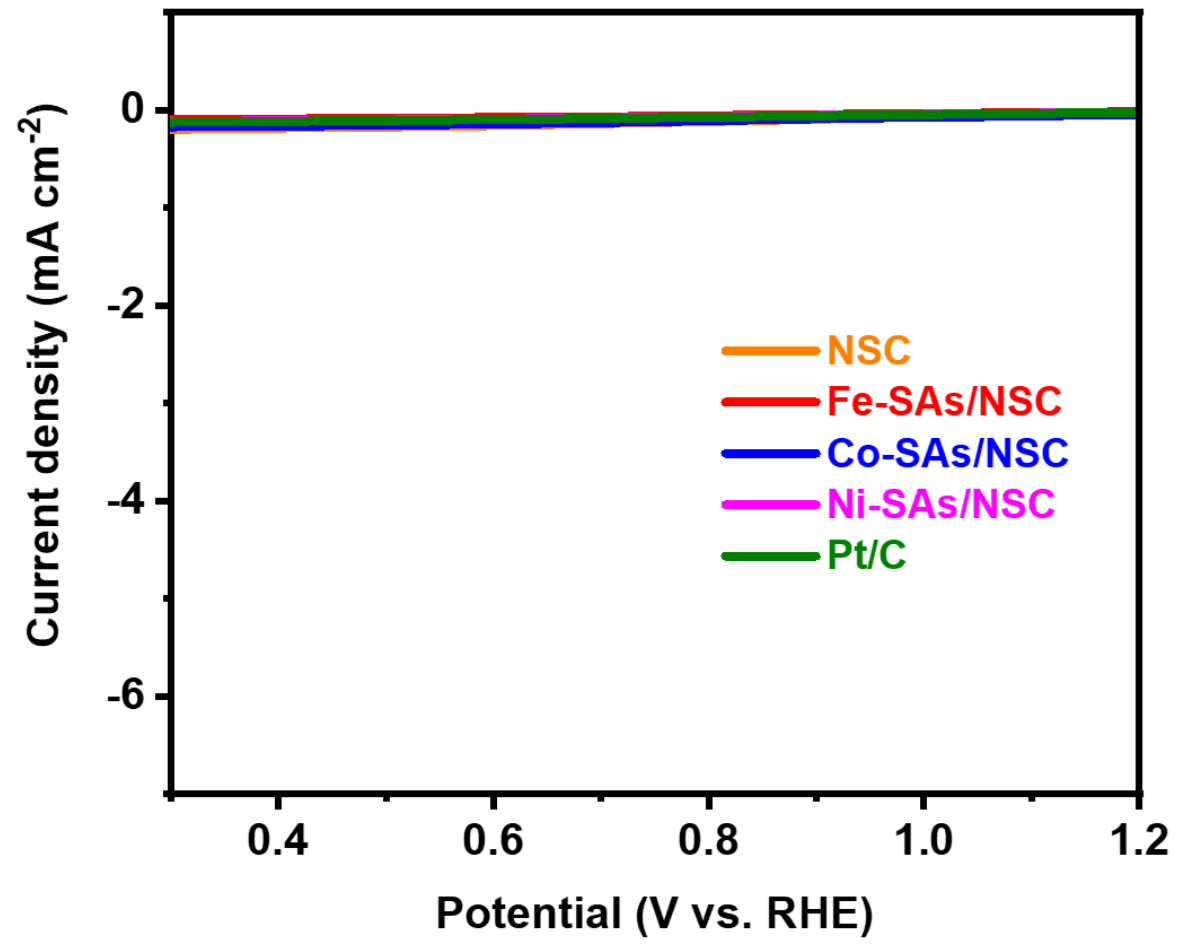

Figure S21. Polarization curves of NSC, Ni-SAs/NSC, Co-SAs/NSC, Fe-SAs/NSC and Pt/C in $\mathrm{N}_{2}$-saturated $0.1 \mathrm{M} \mathrm{KOH}$ solution with a rotation rate of $1600 \mathrm{rpm}$. 


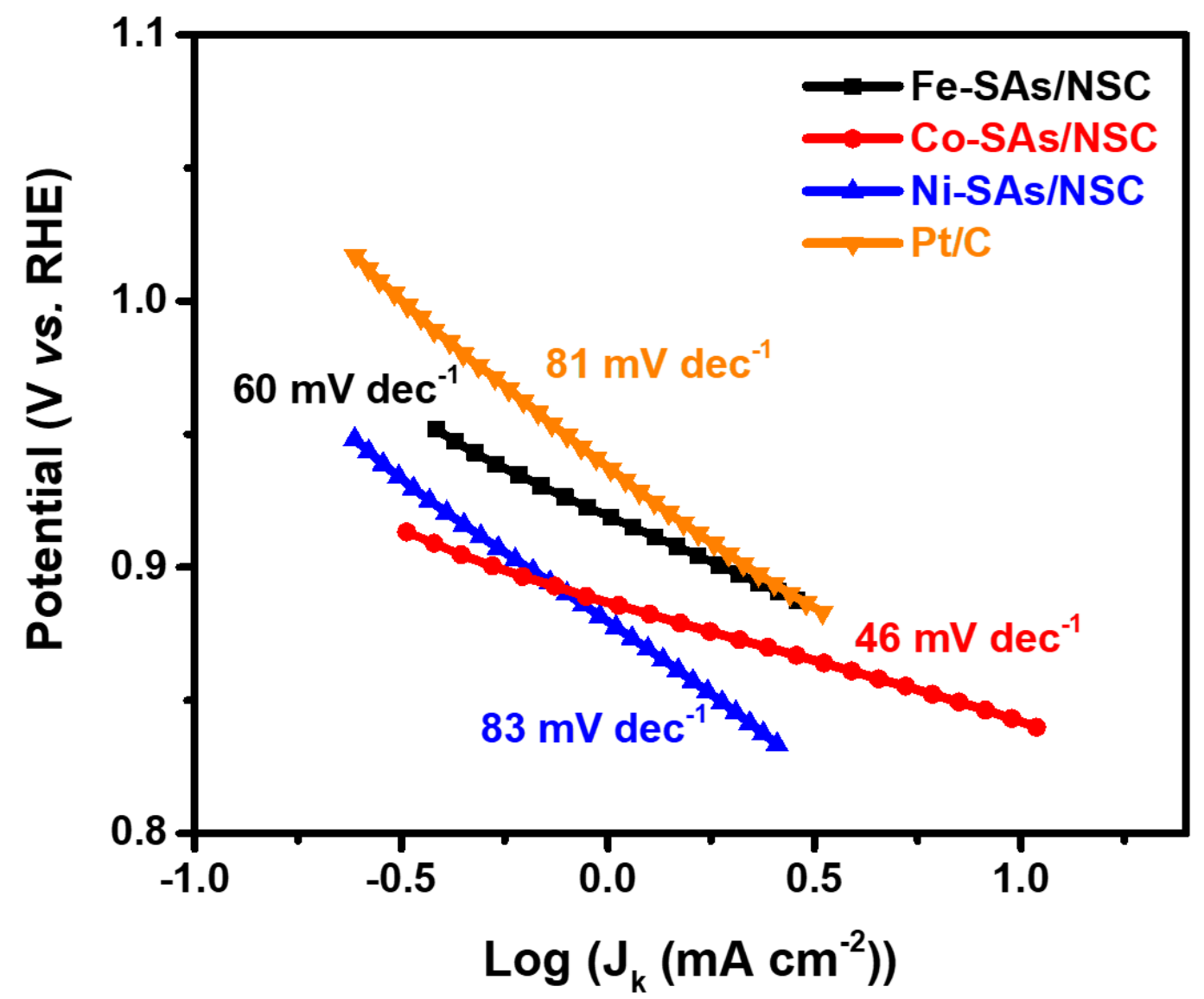

Figure S22. The Tafel slope of Fe-SAs/NSC, Co-SAs/NSC, Ni-SAs/NSC and Pt/C. 


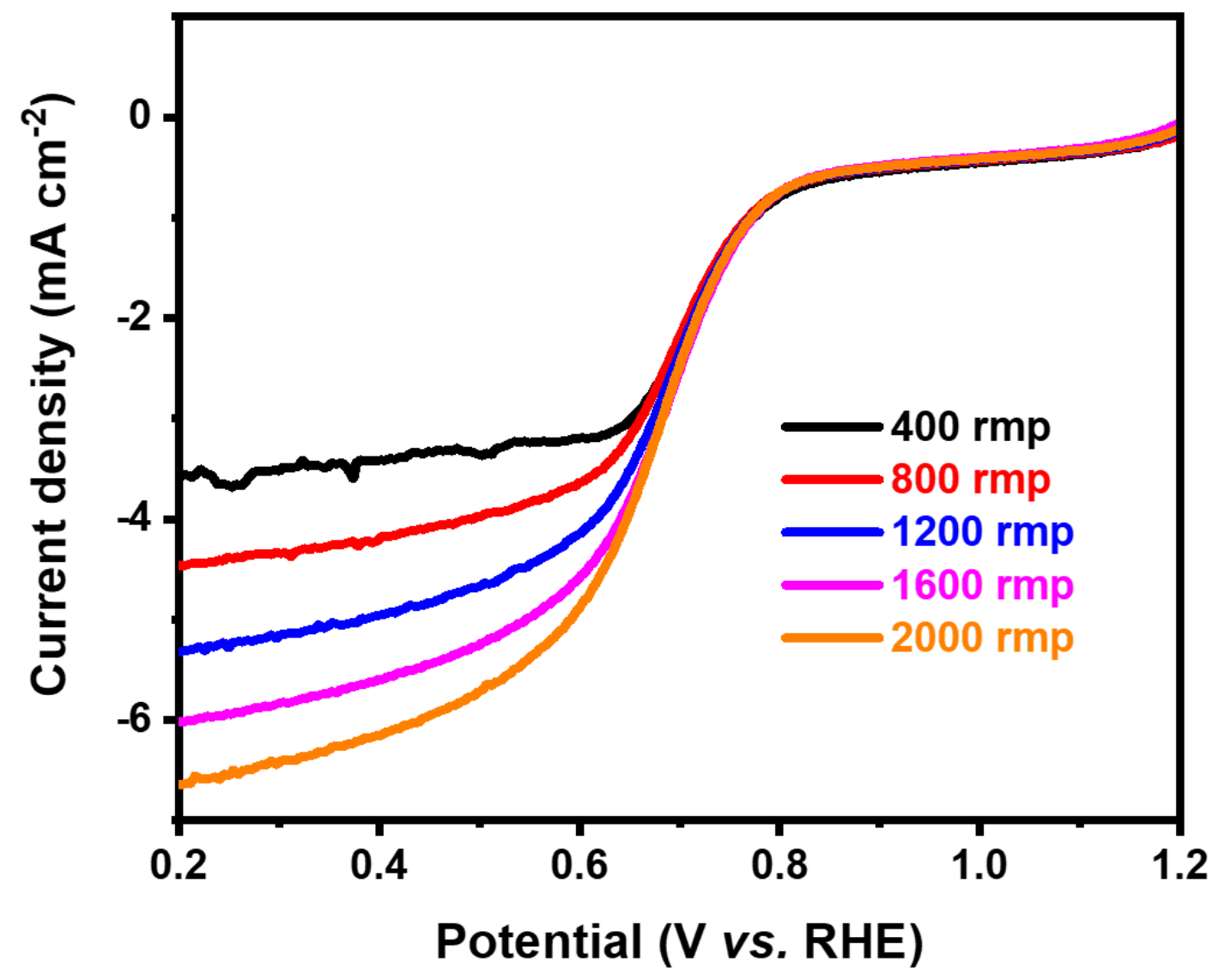

Figure S23. LSV curves of Fe-SAs/NSC at various rotation rates in $0.5 \mathrm{M} \mathrm{H}_{2} \mathrm{SO}_{4}$ solution. 


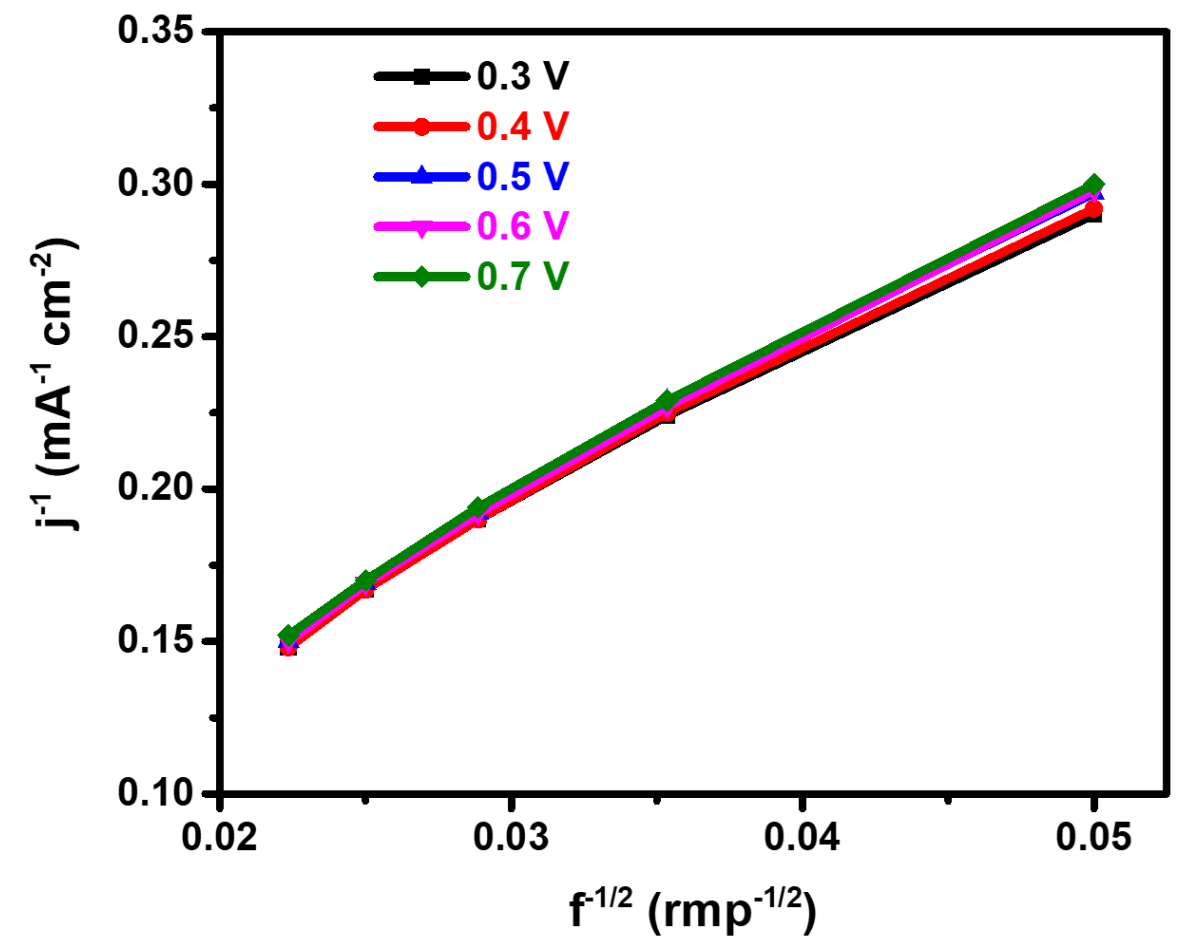

Figure S24. Koutecky-Levich plots and electron transfer number of Fe-SAs/NSC. 


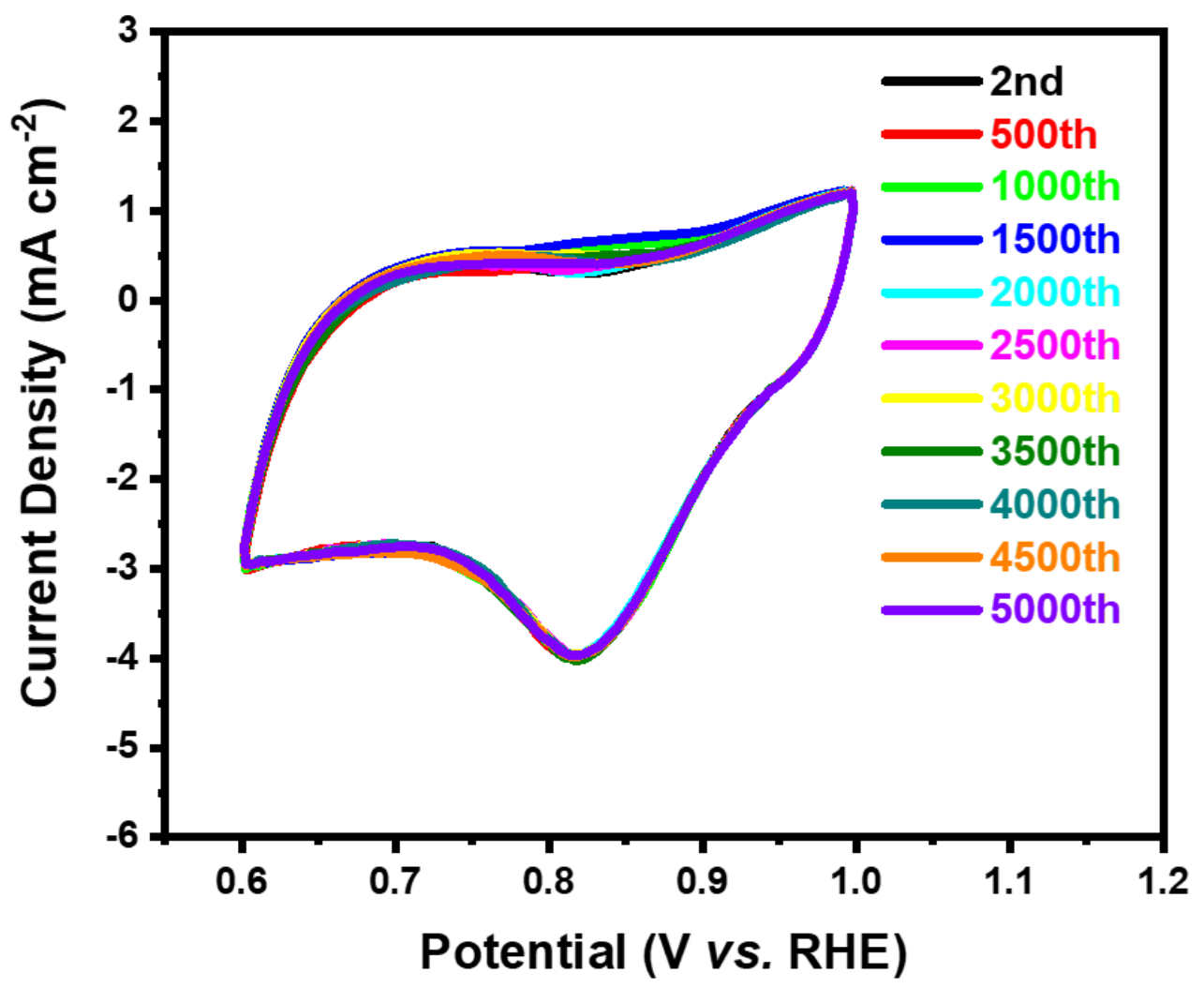

Figure S25. Durability $\mathrm{CV}$ curves of $\mathrm{Fe}-\mathrm{SAs} / \mathrm{NSC}$ at $\mathrm{O}_{2}$ atmosphere. 

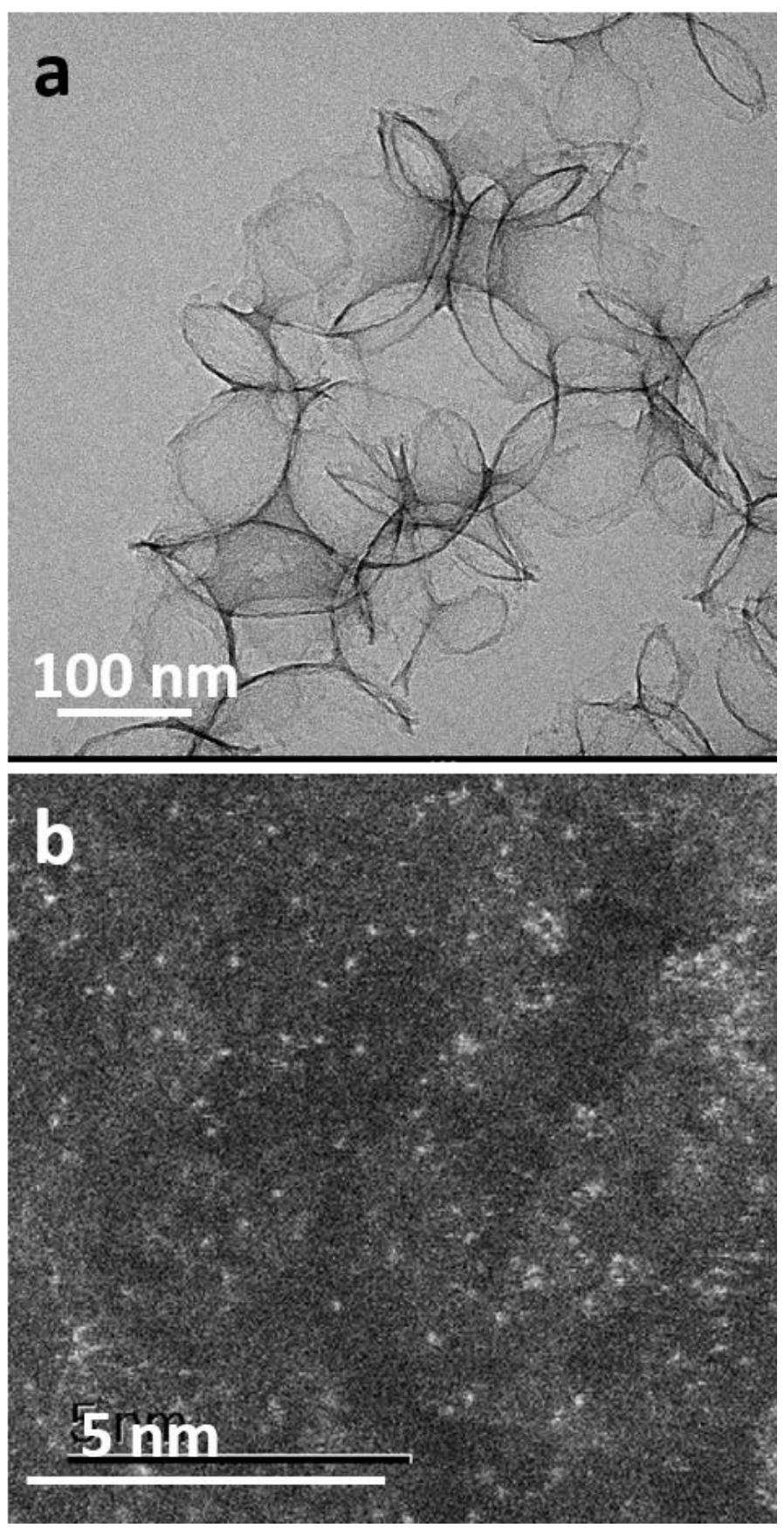

Figure S26. The TEM and HAADF-STEM images of Fe-SAs/NSC after stability test. 


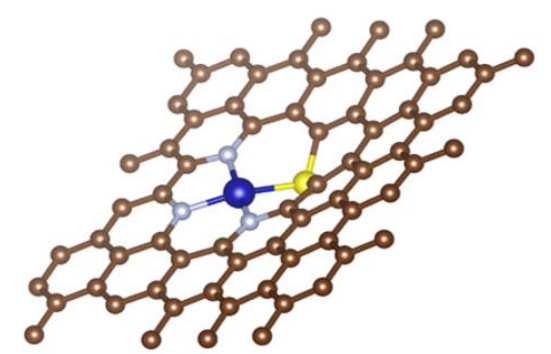

$\mathrm{O}_{2}+\mathrm{H}_{2} \mathrm{O}+\mathrm{e}^{-} \mathrm{OH}^{-}$
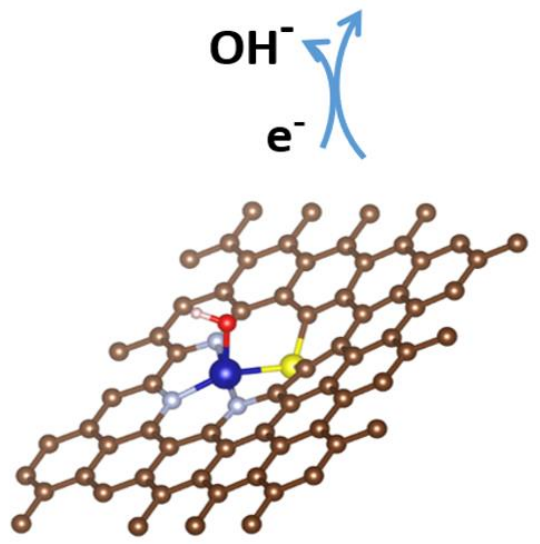

$\odot$ Co $\odot$

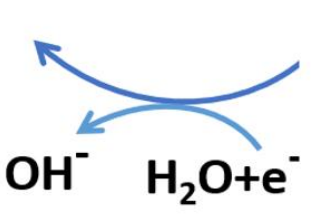

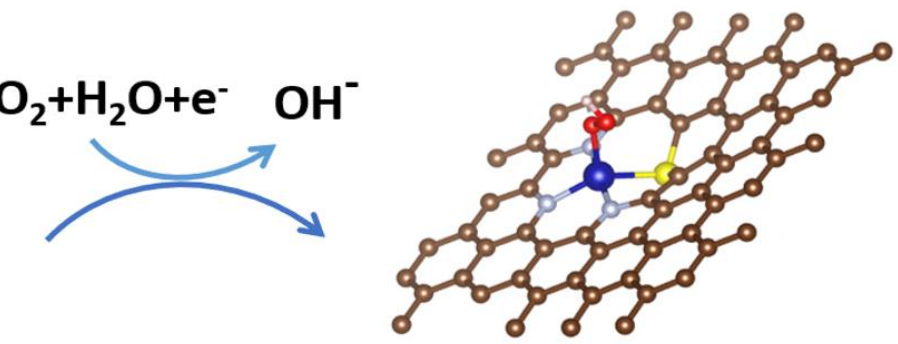
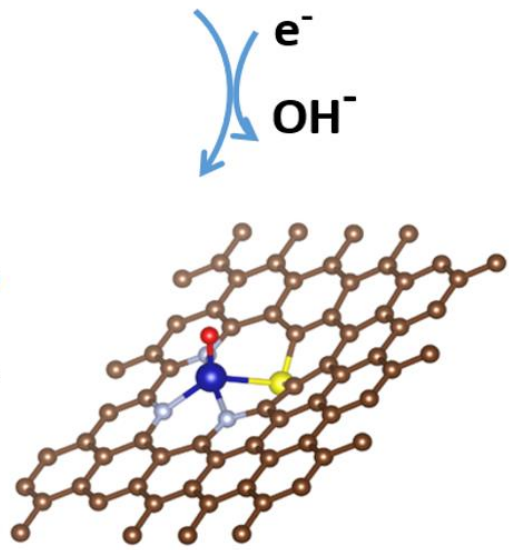

$\mathbf{C} \circ \mathbf{N} \bigcirc \mathbf{S} \circ \mathbf{O} \circ \mathbf{H}$

Figure S27. Proposed reaction scheme with the intermediates having optimized geometry of Co-SAs/NSC toward alkaline ORR. (C: brown, N: light blue, Co: blue, S: yellow, O: red, H: white). 

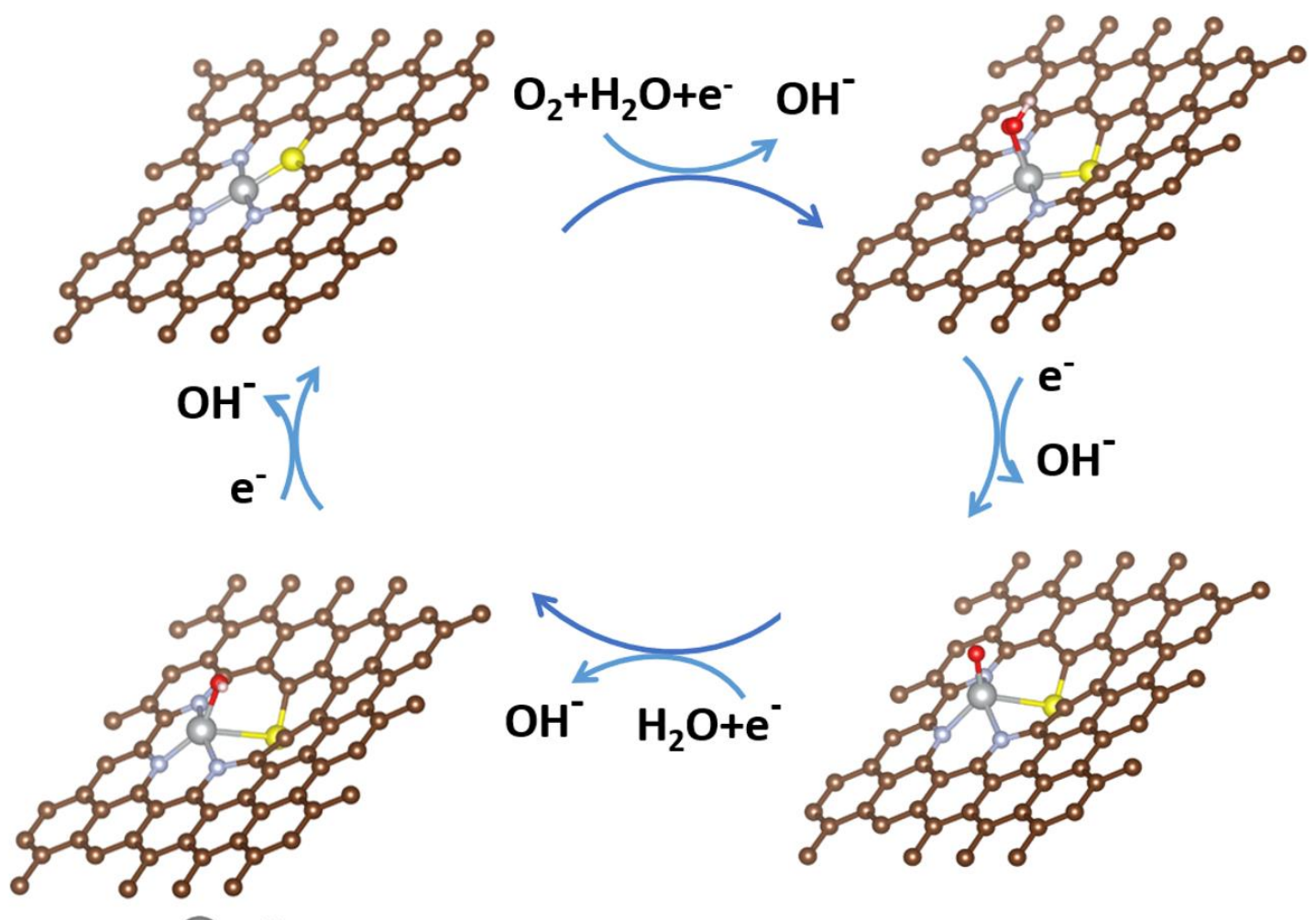

Co $\odot$ C $\odot$ N $\bigcirc$ S $\odot$ O $\circ$ H

Figure S28. Proposed reaction scheme with the intermediates having optimized geometry of Ni-SAs/NSC toward alkaline ORR. (C: brown, N: light blue, Ni: grey, S: yellow, O: red, H: white). 

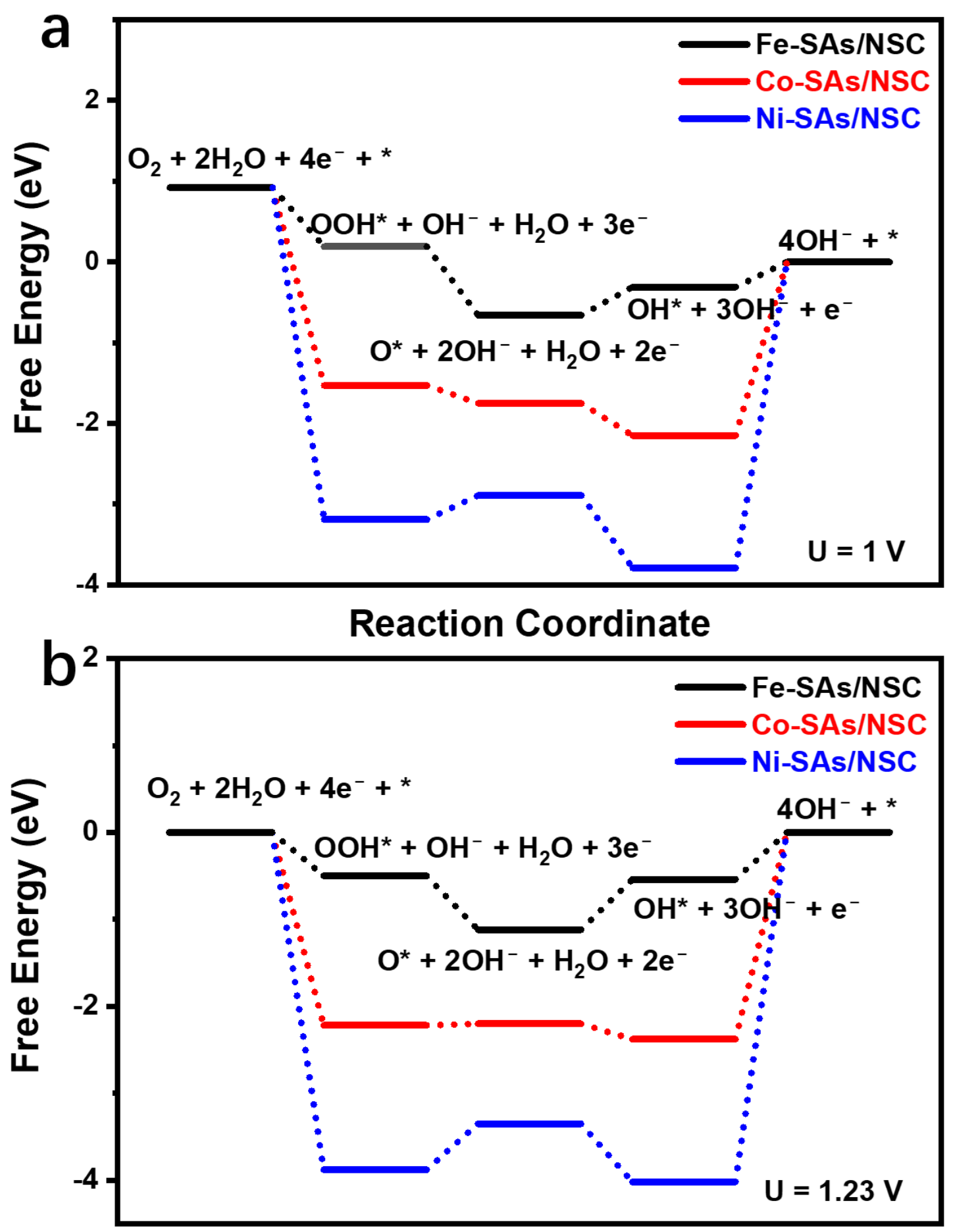

Reaction Coordinate

Figure S29. Free energy diagram of the oxygen reduction reaction (ORR) on Fe-SAs/NSC, Co-SAs/NSC and Ni-SAs/NSC, based on a. $\mathrm{U}=1.0 \mathrm{~V}$ and b. $\mathrm{U}=1.23 \mathrm{~V}$. 
Table S1. Fitting result of FT-EXAFS curves shown in Figure 3.

\begin{tabular}{|c|c|c|c|c|}
\hline & Bond type & N & R $(\AA)$ & $\sigma^{2} \times 10^{-3}\left(\AA^{2}\right)$ \\
\hline & Fe-N1 & $2.044 \pm 0.41$ & $1.6629 \pm 0.017$ & $2.72 \pm 0.544$ \\
\hline & Fe-N2 & $1.968 \pm 0.39$ & $2.0471 \pm 0.020$ & $1.90 \pm 0.380$ \\
\hline Co-SAs/NSC & Co-N & $2.604 \pm 0.52$ & $1.8838 \pm 0.019$ & $1.12 \pm 0.224$ \\
\hline & Co-S & $1.400 \pm 0.28$ & $2.1967 \pm 0.022$ & $0.02 \pm 0.004$ \\
\hline & Ni-N & $2.676 \pm 0.54$ & $1.74826 \pm 0.017$ & $0.805 \pm 0.161$ \\
\hline & Ni-S & $1.120 \pm 0.22$ & $1.98910 \pm 0.019$ & $1.035 \pm 0.207$ \\
\hline
\end{tabular}

The local structure information of Fe-SAs/NSC, Co-SAs/NSC, and Ni-SAs/NSC samples were collected from measuring $\mathrm{Fe}, \mathrm{Co}$, and $\mathrm{Ni}$ edges XAS spectra, respectively. $\mathrm{N}$ is the coordination number; $\mathrm{R}$ is interatomic distance (the bond length between $\mathrm{X}$-ray absorbing atoms and surrounding coordination atoms); $\sigma^{2}$ is Debye-Waller factor (a measure of thermal and static disorder in absorber-scatterer distances). 
Table S2. Fitting result of FT-EXAFS curves shown in Figure S18.

\begin{tabular}{|c|c|c|c|c|}
\hline & Bond type & $\mathbf{N}$ & $\mathbf{R}(\AA)$ & $\sigma^{2} \times 10^{-3}\left(\AA^{2}\right)$ \\
\hline $\begin{array}{c}\text { Fe-organic } \\
\text { complex }\end{array}$ & Fe-N & $\mathbf{3 . 6 6 8} \pm \mathbf{0 . 7 3 3 6}$ & $\mathbf{1 . 7 0 \pm 0 . 0 1 7}$ & $\mathbf{0 . 0 1 4 8 8} \pm \mathbf{0 . 0 0 2 9}$ \\
\hline Fe(NO3)3 & Fe-O & $\mathbf{2 . 8 6 0 \pm 0 . 5 7 2 0}$ & $\mathbf{2 . 0 3} \pm \mathbf{0 . 0 2 0}$ & $\mathbf{0 . 0 0 4 1 8} \pm \mathbf{0 . 0 0 0 8}$ \\
\hline Stacking & Fe-Fe & $\mathbf{1 . 2 2 4} \pm \mathbf{0 . 2 4 4 8}$ & $\mathbf{2 . 7 0 \pm 0 . 0 2 7}$ & $\mathbf{0 . 0 0 0 7 0} \pm \mathbf{0 . 0 0 0 1}$ \\
\hline
\end{tabular}

$\mathrm{N}$ is the coordination number; $\mathrm{R}$ is interatomic distance (the bond length between $\mathrm{X}$-ray absorbing atoms and surrounding coordination atoms); $\sigma^{2}$ is Debye-Waller factor (a measure of thermal and static disorder in absorber-scatterer distances). 
Table S3. DFT result of the Binding energies $\left(\mathrm{E}_{\mathrm{b}}\right)$ for different types of single-atom catalysts.

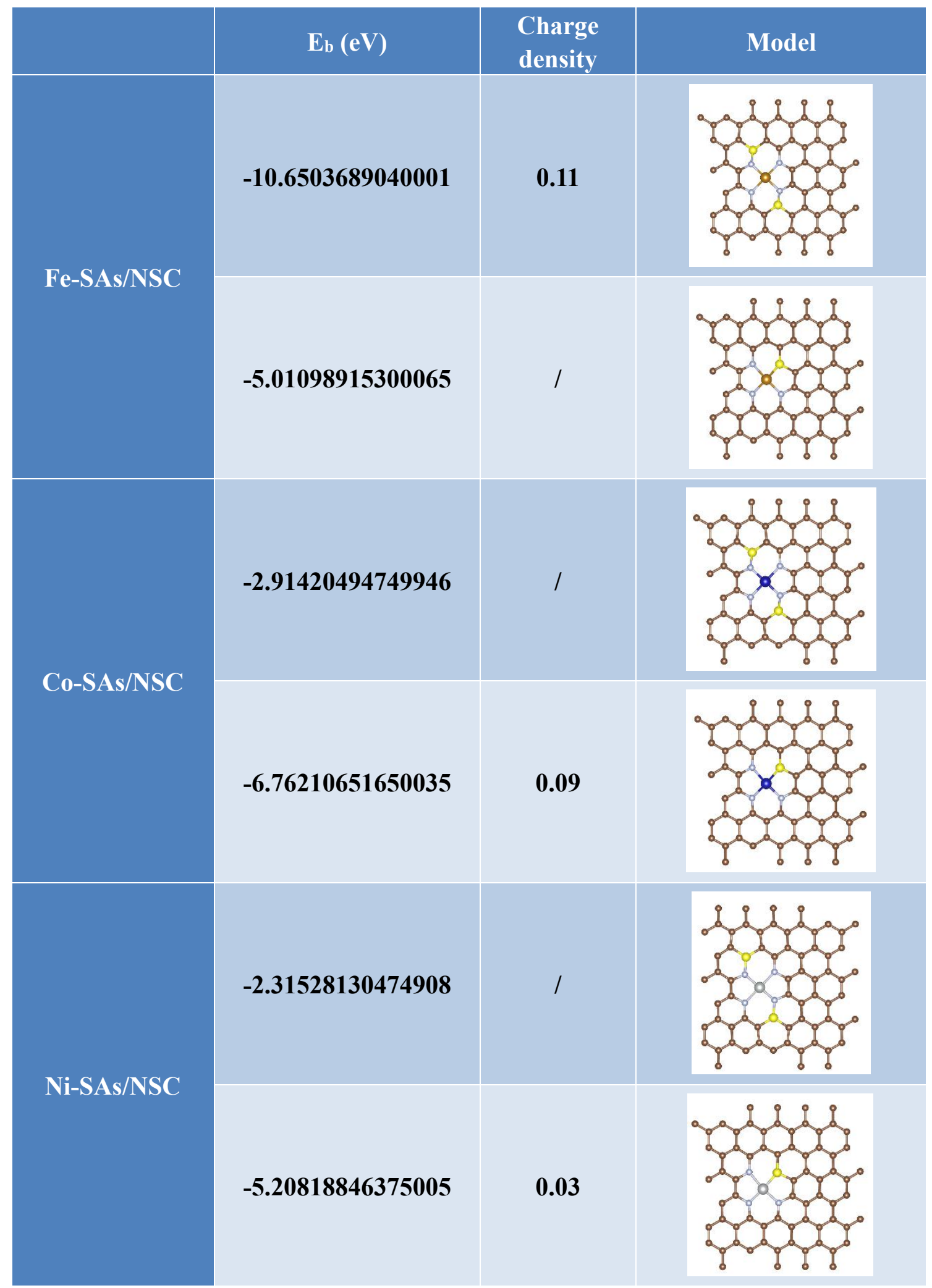


Table S4. Comparison of ORR activities of reported materials in $0.1 \mathrm{M} \mathrm{KOH}$.

\begin{tabular}{|c|c|c|c|c|c|}
\hline Entry & Catalysts & Eonset (V) & $\mathbf{E}_{1 / 2}(\mathbf{V})$ & $\begin{array}{c}J_{\text {limiting }} \\
\left(\mathrm{mA} \mathrm{cm} \mathbf{c m}^{-2}\right)\end{array}$ & Reference \\
\hline 1 & Fe-SAs/NSC & 1.00 & 0.87 & 6.00 & This work \\
\hline 2 & Co-SAs/NSC & 0.95 & 0.86 & 4.50 & This work \\
\hline 3 & Ni-SAs/NSC & 0.96 & 0.82 & 4.30 & This work \\
\hline 4 & $\begin{array}{l}\text { FeNC-S- } \\
\mathrm{Fe}_{\mathrm{x}} \mathrm{C} / \mathrm{Fe}\end{array}$ & 1.05 & 0.873 & 5.45 & $\begin{array}{c}\text { Adv. Mater. 2018, } \\
1804504\end{array}$ \\
\hline 5 & Fe@N-C-700 & 0.94 & 0.83 & 6.10 & $\begin{array}{c}\text { Nano Energy 2015, 13, } \\
387\end{array}$ \\
\hline 6 & $\mathrm{~S}, \mathrm{~N}-\mathrm{Fe} / \mathrm{N} / \mathrm{CCNT}$ & I & 0.85 & 6.68 & $\begin{array}{c}\text { Angew. Chem. Int. Ed. } \\
\text { 2017, 56, 610-614 }\end{array}$ \\
\hline 7 & Fe-ISA/SNC & l & 0.896 & $\sim 5.70$ & $\begin{array}{c}\text { Adv. Mater. 2018, } 30, \\
1800588\end{array}$ \\
\hline 8 & Fe-N-C HNS & 1.046 & 0.87 & $\sim 5.90$ & $\begin{array}{c}\text { Adv. Mater. 2018, } \\
1806312\end{array}$ \\
\hline 9 & Fe-ISAs/CN & 0.990 & 0.90 & $\sim 6.10$ & $\begin{array}{c}\text { Angew. Chem. 2017, } \\
\text { 129, 1-6 }\end{array}$ \\
\hline 10 & Fe2-Z8-C & 0.985 & 0.871 & $\sim 6.00$ & $\begin{array}{c}\text { Angew. Chem. Int. Ed. } \\
\text { 2018, 57, 1204-1208 }\end{array}$ \\
\hline 11 & FeSAs/PTF-600 & 1.01 & 0.87 & 5.51 & $\begin{array}{c}\text { ACS Energy Lett. 2018, } \\
\text { 3, 883-889 }\end{array}$ \\
\hline 12 & $\begin{array}{c}\text { Fe-NGM/C-Fe } \\
\text { SAC }\end{array}$ & 1.05 & 0.86 & l & $\begin{array}{c}\text { Chem. Mater. 2017, 29, } \\
9915\end{array}$ \\
\hline 13 & Fe-N-C-900 & 0.990 & 0.927 & l & $\begin{array}{c}\text { Adv. Energy Mater. } \\
\text { 2018, } 1801956\end{array}$ \\
\hline 14 & $\mathrm{Cu}-\mathrm{SAs} / \mathrm{N}-\mathrm{C}$ & I & 0.895 & $\sim 5.5$ & $\begin{array}{c}\text { Nat. Catal. 2018, } \\
\text { 1, 781-786 }\end{array}$ \\
\hline
\end{tabular}


Table S5. The stability of single Fe or other atoms-based catalysts towards ORR.

\begin{tabular}{|c|c|c|c|}
\hline & Catalysts & $\begin{array}{l}\text { Stability (no } \\
\text { obvious decay } \\
\quad \text { in } E_{1 / 2} \text { ) }\end{array}$ & References \\
\hline 1 & $\begin{array}{c}\text { Fe-SAs/NPS- } \\
\text { HC }\end{array}$ & 5000 cycles & Nat. Commun,2018, 9, 5422 \\
\hline 2 & $\begin{array}{c}\mathrm{Fe}-\mathrm{N}-\mathrm{C} \\
\text { HNSs }\end{array}$ & 10000 cycles. & Adv. Mater. 2018, 1806312 \\
\hline 3 & Fe-ISA/SNC & 15000 cycles & $\begin{array}{c}\text { Adv. Mater. 2018, } 30 \\
1800588\end{array}$ \\
\hline 4 & $\mathrm{Fe}-\mathrm{ISAs} / \mathrm{CN}$ & $\begin{array}{l}5000 \text { cycles the } \\
\text { change of } E_{1 / 2} \\
(\text { ca. } 2 \mathrm{mV})\end{array}$ & $\begin{array}{l}\text { Angew. Chem. Int. Ed., } \\
\text { 2017, 56, 6937-6941 }\end{array}$ \\
\hline 5 & $\mathrm{Cu}-\mathrm{SAs} / \mathrm{N}-\mathrm{C}$ & 5000 cycles & Nat. Cataly. 2018, 1, 781-786 \\
\hline 6 & Fe-NC SAC & 5000 cycles & Nat. Commun. 2019, 10, 1278 \\
\hline 7 & Co SAs/N-C & 5000 cycles & $\begin{array}{c}\text { Angew. Chem. Int. Ed. 2016, } \\
55,10800-10805\end{array}$ \\
\hline
\end{tabular}

\section{References}

1. Zhao, Y.; Zhang, J.; Guo, X.; Fan, H.; Wu, W.; Liu, H.; Wang, G., Fe 3 C@ nitrogen doped CNT arrays aligned on nitrogen functionalized carbon nanofibers as highly efficient catalysts for the oxygen evolution reaction. J. Mater. Chem. A 2017, 5, 19672-19679.

2. Xia, B. Y.; Yan, Y.; Li, N.; Wu, H. B.; Lou, X. W. D.; Wang, X., A metal-organic framework-derived bifunctional oxygen electrocatalyst. Nat. Energy 2016, 1, 15006.

3. Cui, X.; Ren, P.; Deng, D.; Deng, J.; Bao, X., Single layer graphene encapsulating nonprecious metals as high-performance electrocatalysts for water oxidation. Energy Environ. Sci. 2016, 9, 123-129.

4. Fan, L.; Liu, P. F.; Yan, X.; Gu, L.; Yang, Z. Z.; Yang, H. G.; Qiu, S.; Yao, X., Atomically isolated nickel species anchored on graphitized carbon for efficient hydrogen evolution electrocatalysis. Nat. Commun. 2016, 7, 10667. 